\title{
Los culpables tienen nombre y apellido. Luis Gutiérrez Oropeza y el 2 de octubre de 1968*
}

The Culprits Have a First and Last Name. Luis Gutiérrez Oropeza and October 2, 1968

\author{
Anuar Israel Ortega Galindo \\ Seminario Nacional de Movimientos Estudiantiles \\ Universidad Nacional Autónoma de México \\ anvardo13@yahoo.com.mx
}

Recibido: 7 de febrero de 2018 • Aprobado: 17 de febrero de 2018

Cómo citar este artículo: Anuar Israel Ortega Galindo, "Los culpables tienen nombre y apellido. Luis Gutiérrez Oropeza y el 2 de octubre de 1968", en Legajos. Boletín del Archivo General de la Nación, núm. 17 (septiembrediciembre 2018), pp. 11-54.

\section{Resumen}

A 50 años del movimiento popular estudiantil de 1968 se hace necesario determinar la responsabilidad de cada uno de los participantes, en los trágicos sucesos del 2 de octubre, para así cicatrizar una herida aún abierta. Este artículo examina la forma en la que en la versión militar se delineó al enemigo, con lo cual se justificó la utilización de métodos violentos para finiquitar la peligrosa efervescencia popular. Un personaje importantísimo en la provocación desarrollada en la Plaza de las Tres Culturas de Tlatelolco fue el capitán Luis Gutiérrez Oropeza, jefe, entonces, del Estado Mayor Presidencial.

Palabras clave: movimiento estudiantil de 1968, masacre del 2 de octubre, historiografía militar, conjura internacional

\section{Abstract}

Fifty years after the popular student movement of 1968, it is necessary to determine the responsibility of each one of the participants, in the tragic events of October 2, in order to heal a still open wound. This article examines in the military version the way in which the enemy was delineated, which was used to justify employing violent methods to end the dangerous popular effervescence. A very important man in the provocation in the Plaza de las Tres Culturas in Tlatelolco was Captain Luis Gutiérrez Oropeza, then Chief of the Presidential General Staff at that time.

Keywords: Student movement of 1968, massacre of October 2 , military historiography, international plot

* Extracto de "La historiografía oficial sobre el movimiento estudiantil de 1968 y Luis Gutiérrez Oropeza", tesis de licenciatura inédita en hwistoria, Ciudad de México, Facultad de Filosofia y Letras de la Universidad Nacional Autónoma de México, 2018. 


\section{Introducción}

El presente texto desarrolla un análisis de la historiografía militar sobre el movimiento estudiantil de 1968 - las obras analizadas son las de Manuel Urrutia Castro, Alfonso Corona del Rosal y Luis Gutiérrez Oropeza-, que en sintonía con la versión oficial, explicó los sucesos como parte de una conjura internacional. La hipótesis a verificar es la de que a partir de valoraciones morales se justificó el uso de la violencia sin remordimientos. Se construyó una narrativa para despersonificar al oponente y entonces aplicar, así, medidas duras, dolorosas, pero necesarias. Los trabajos de Urrutia Castro y Corona del Rosal se analizan parcialmente; no es el caso del de Gutiérrez Oropeza, jefe del Estado Mayor Presidencial (EMP) de 1964 a 1970, de quien hay evidencias y señalamientos de ser responsable de apostar francotiradores que abrieron fuego en la Plaza de las Tres Culturas de Tlatelolco.

Han pasado 50 años del trágico episodio, desde entonces, las evidencias salen a la luz paulatinamente, en consonancia con ese inacabado proceso; este texto ofrece una interpretación en la que los perpetradores del crimen de Estado muestran un rostro identificable.

\section{Conjura internacional, el enemigo en casa}

La versión oficial sobre el movimiento estudiantil de 1968 es un conjunto de piezas configuradas desde las oficinas de gobierno y que al embonar arrojan una explicación que se sustenta en la supuesta existencia de una conspiración internacional consagrada al sabotaje de las xix Olimpiadas en México y, eventualmente, al derrocamiento del gobierno legalmente constituido. Tutelada por la Secretaría de Gobernación, la versión oficial está presente en notas periodísticas, editoriales, relatos, novelas, propagandas, discursos y hasta estudios históricos. De acuerdo con especialistas en historiografía, 
dicha versión surgió por la necesidad de: "explicar [y justificar], la solución oficial al conflicto estudiantil".

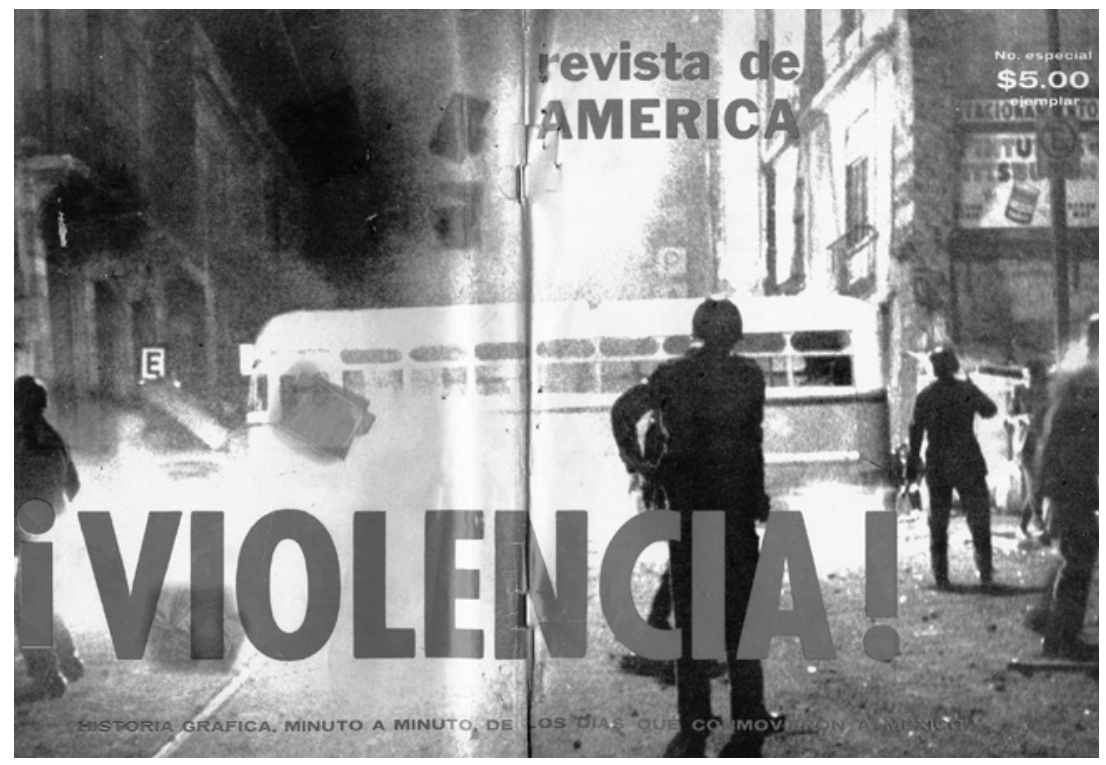

Imagen 1. Portada de la Revista de América, edición especial, agosto 1968. Colección cidDOC, Movimiento Estudiantil, Tarsicio Ocampo, Biblioteca Daniel Cosío Villegas de El Colegio de México, Ciudad de México.

A pesar de que la versión oficial está desacreditada, olvidada en el mar del pasado, vale la pena revisarla porque refleja la razón y lógica detrás de la actuación gubernamental. La noción de conjura tuvo profundas repercusiones en la manera en cómo se entendió el problema y de las formas en que debió resolverse. Dice Sergio Aguayo que el régimen mexicano modificó su percepción del movimiento estudiantil, de adversario a enemigo, a raíz de la suma de agravios que la irreverencia juvenil impuso en la conducta del movimiento estudiantil. En agosto lo definió como enemigo y en septiembre fue cercado en la capital;

${ }^{1}$ Tasso, La historiografia oficial de 1968, pp. 60 y 61. 
entonces empezaron las incursiones militares para arrebatarle territorios, ${ }^{2}$ y finalmente, en octubre fue brutalmente aplastado en la Plaza de las Tres Culturas del conjunto urbano presidente Adolfo López Mateos de Nonoalco Tlatelolco.

\section{La historiografía militar sobre el movimiento estudiantil de 1968}

Algunos especialistas consideran que "la experiencia de 1968 trajo como consecuencia que nunca más volviera a utilizarse el ejército en disturbios civiles", ${ }^{3}$ la pérdida de confianza y autoridad sobre la población no lo valía, "el uso constante del ejército en labores policiacas produjo una reacción popular de desprecio a los soldados". "En los años posteriores disminuyó la presencia militar en la contención de la oposición, especialmente durante la guerra sucia, y aumentaron y proliferaron los grupos paramilitares, brigadas de exterminio, organizados y dirigidos por militares y jefes policiacos. La lección de Tlatelolco implicó una modificación en los métodos de represión.

A eso se debe la existencia de varios textos escritos por militares sobre los acontecimientos de 1968. Son trabajos que sirven para formular alegatos en favor del ejército. Trataron de ofrecer versiones que esclarecieran los acontecimientos, aunque, como veremos más adelante, replicaron la versión paranoica de la conjura internacional. Para el objeto de este trabajo serán revisados tres textos, cuyos autores son militares que ocuparon cargos importantes durante la administración de Gustavo Díaz Ordaz (1964-1970). Los materiales en cuestión son Mis memorias politicas de Alfonso Corona del Rosal que fungió como regente del Departamento del Distrito Federal durante el conflicto estudiantil. Trampa en Tlatelolco del general Manuel Urrutia Castro que

\footnotetext{
${ }^{2}$ Aguayo, De Tlatelolco a Ayotzinapa, p. 64.

${ }^{3}$ Villalpando, "Política y ejército, 1945-1994", p. 333.

4 Álvarez Garín, La estela de Tlatelolco, p. 235.
} 
estuvo presente en operativos militares en distintas escuelas en huelga; participó en la toma de las instalaciones de Ciudad Universitaria, el 18 de septiembre; en las batallas por el casco de santo Tomás del Instituto Politécnico Nacional, los días 23 y 24 de septiembre, y en la Plaza de las Tres Culturas de Tlatelolco el 2 de octubre. Y, por último, La realidad de los acontecimientos de 1968 del jefe del Estado Mayor Presidencial (1964-1970) Luis Gutiérrez Oropeza.

Los autores declaran rigurosidad, pero conceden valor probatorio a explicaciones institucionales y personales. Hay respaldo documental de lo que se afirma, pero eso no les concede objetividad. La documentación burocrática no está exenta de rumores y prejuicios, como en los casos de Corona del Rosal y Gutiérrez Oropeza.

Manuel Urrutia construye una cronología del movimiento estudiantil acompañada de "pruebas irrefutables" provenientes de informes de la Secretaría de la Defensa y recortes periodísticos que explican y respaldan la actuación oficial. Lo más destacado son las entrevistas a mandos militares que actuaron en las operaciones de contención del movimiento estudiantil y que expresan desconocer verdaderamente lo que sucedió. Escrito entre 1969 y 1970 desarrolla la tesis de que las fuerzas más perversas dentro del ejército tendieron una trampa en la Plaza de las Tres Culturas a éste, a estudiantes y a vecinos. Fue una trampa perpetrada por personajes siniestros e incognitos que nunca muestran un rostro concreto.

El hidalguense Alfonso Corona del Rosal, concedió un espacio en sus Memorias Políticas a los acontecimientos de 1968. Justifica la manera en que actuó el gobierno de Díaz Ordaz durante los meses de julio a octubre. Para sustentar sus dichos recupera informes, cartas y notas periodísticas. Sin embargo, no logra desprenderse de la versión personalísima. La explicación se reduce a una disputa entre agitadores y legítimas autoridades. El argumento superior es que entre los estudiantes hubo agitadores e infiltrados que anhelaban impedir la realización de la olimpiada, pues deseaban sacar provecho del reflector internacional. La conjura internacional está presente en México y 


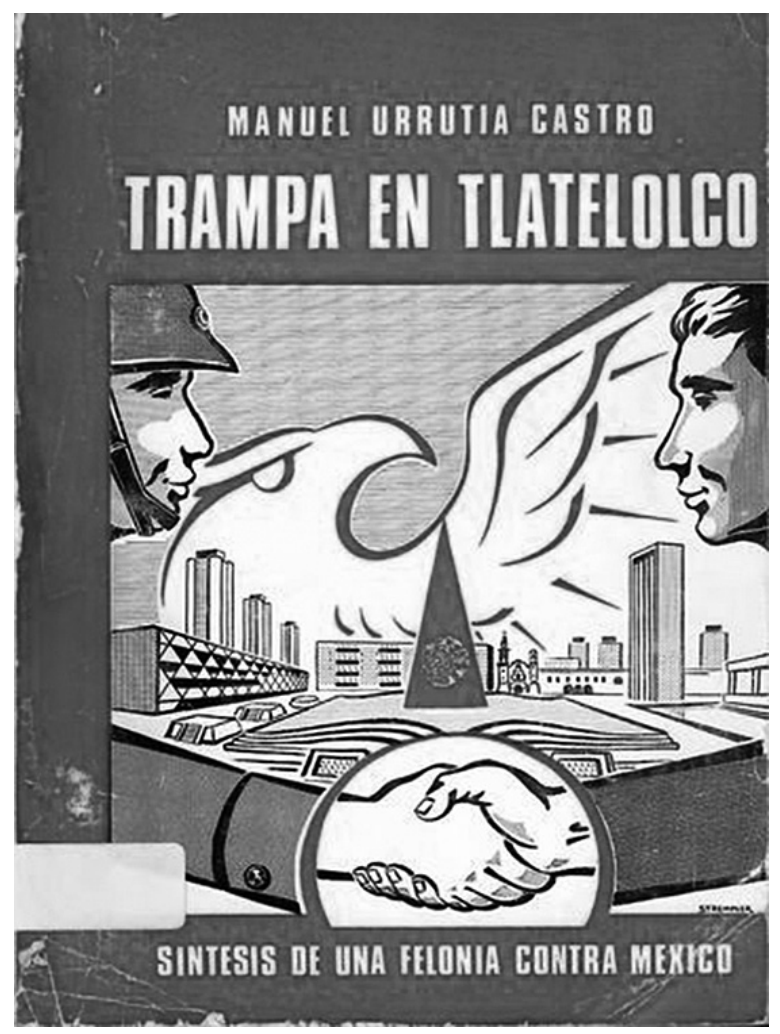

Imagen 2. Manuel Urrutia Castro, Trampa de Tlatelolco. Sintesis de una felonía contra México, México, M. Urrutia Castro [1981].

dará el golpe de timón para "establecer un gobierno socialista". ${ }^{5} \mathrm{La}$ evidencia está a la vista de todos: "numerosos manifestantes portaban retratos de Ernesto "Che" Guevara y de otros destacados comunistas. En algunos carteles, se atacaba violentamente al presidente de la República; era obvio que buscaban desestabilizar al gobierno". ${ }^{6}$ Para Corona del Rosal, el gobierno respondió a la conspiración con

${ }^{5}$ Corona del Rosal, Mis memorias políticas, p. 276.

${ }^{6}$ Corona del Rosal, Mis memorias políticas, p. 239. 


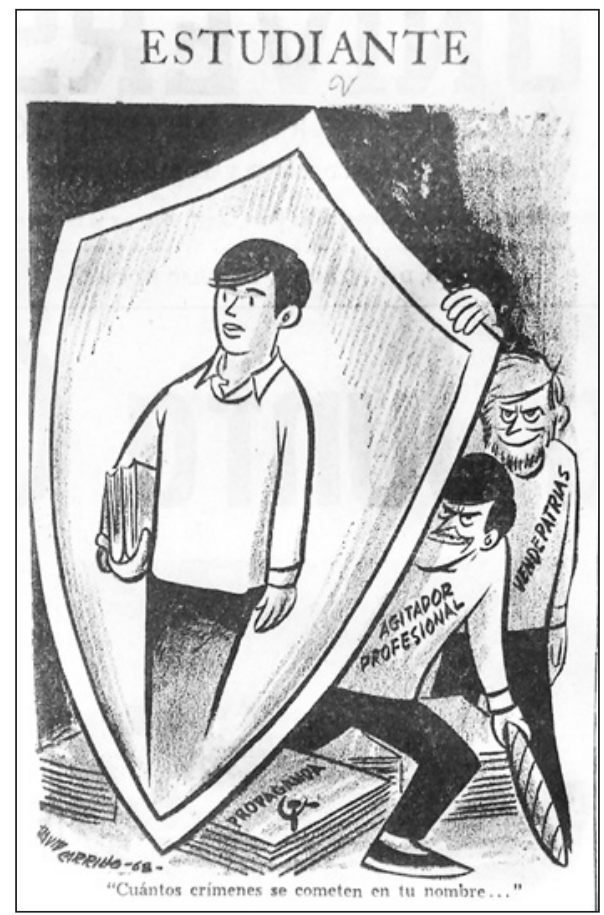

Imagen 3. "Estudiante", El Universal, 29 de julio de 1968, p. 3, Archivo General de la Nación, fondo gobernación, sección DGIPS, caja 2949-A.

distintas estrategias, se movió entre la persuasión y la represión. En su descripción de los acontecimientos sobredimensiona las ocasiones en que hubo acercamiento para establecer un diálogo y se lamenta de que no se haya podido llegar a nada. ${ }^{7}$ Como exponente de la versión

${ }^{7}$ La manera en que se ejerció la representación en el Consejo Nacional de Huelga, sin líderes autorizados para hablar en nombre de todo el movimiento estudiantil, representó un serio problema, "lamentablemente, el encuentro no produjo ningún resultado positivo, porque estos jóvenes no contaban con el respaldo de la mayoría de sus compañeros. En ocasiones llegué a pensar que los dirigentes estudiantiles no tenían deseos de lograr una solución al problema". Corona del Rosal, Mis memorias políticas, p. 216. 
oficial justifica el uso de la violencia: "Nunca hubo agresiones injustificadas; solo cuando se suscitaron los hechos violentos, no pudieron gozar de impunidad los provocadores". ${ }^{8}$

Urrutia, Corona del Rosal y Gutiérrez Oropeza coinciden en tildar a los estudiantes de perniciosos y manipulables, no les confieren aporte o virtud alguna. Urrutia argumenta que la juventud estudiantil estaba "lamentablemente decidida a inmolarse para triunfar". ${ }^{9}$ Corona del Rosal dice del 2 de octubre: "Aquello fue una trampa para buscar víctimas; las víctimas de las que se había hablado desde el principio del conflicto estudiantil, pero que no existían". ${ }^{10}$ Un rasgo de la historiografía militar es que concibe a los estudiantes como objetos, y no como sujetos históricos con libre autodeterminación, carecen de autonomía y libre albedrio, son títeres movidos por fuerzas personificadas o metafísicas. Los planes para sabotear las olimpiadas van desde generar un fracaso y burla a nivel mundial hasta obligar a deponer al gobierno en turno.

A continuación, enuncio los rasgos de explicación desde la versión militar de los acontecimientos. Los verdaderos motores y/o responsables de los acontecimientos, de acuerdo con esta historiografía se resumen en el Cuadro 1 de este artículo.

\section{Luis Gutiérrez Oropeza jefe del Estado Mayor Presidencial}

Luis Gutiérrez Oropeza fue conocido entre la clase política de su tiempo con el apodo de El poblano. Ingresó al Ejército Mexicano en 1938, graduado en artillería por el Heroico Colegio Militar en 1942, ${ }^{11}$ más tarde, en 1956, fue designado ayudante del Estado Mayor

\footnotetext{
${ }^{8}$ Corona del Rosal, Mis memorias políticas, p. 198.

${ }^{9}$ Tasso, La historiografia oficial de 1968, p. 76.

${ }^{10}$ Corona del Rosal, Mis memorias políticas, pp. 196-197.

${ }^{11}$ Roderic Ai Camp, Mexican Political Biographies, p. 332.
} 
Guadro 1. Sobre los actores detrás de la conjura según la historiografía militar.

\begin{tabular}{|c|c|}
\hline \multicolumn{2}{|c|}{ Nacional } \\
\hline Idea & Personaje o institución \\
\hline $\begin{array}{l}\text { Los estudiantes actúan de manera contra- } \\
\text { rrevolucionaria, más parecido a los conser- } \\
\text { vadores o porfiristas, están acompañando } \\
\text { junto con los enemigos históricos del } \\
\text { régimen al sabotaje de la Revolución } \\
\text { mexicana. }\end{array}$ & $\begin{array}{l}\text { Los estudiantes no tienen capacidad propia } \\
\text { ni mucho menos de análisis, están siendo } \\
\text { manipulados por distintos actores: por sus } \\
\text { maestros (con Heberto Castillo como figura } \\
\text { visible), por políticos resentidos (Carlos A. } \\
\text { Madrazo) o por agitadores profesionales } \\
\text { (de las Juventudes Comunistas). }\end{array}$ \\
\hline \multicolumn{2}{|c|}{ Internacional } \\
\hline Idea & Personaje o institución \\
\hline $\begin{array}{l}\text { La revuelta estudiantil se explica, por } \\
\text { la presencia de elementos ajenos, espe- } \\
\text { cialmente extranjeros que buscan dañar } \\
\text { al gobierno revolucionario. México es } \\
\text { rehén de la inercia de la Guerra Fría, de } \\
\text { la disputa de los bloques más poderosos } \\
\text { dentro de un mundo bipolar. }\end{array}$ & $\begin{array}{l}\text { Movidos por fuerzas superiores, los estu- } \\
\text { diantes son rehenes de agitadores profe- } \\
\text { sionales. Y aunque se identifica al Partido } \\
\text { Comunista Mexicano como responsable, } \\
\text { es menospreciado por fuerzas superiores } \\
\text { como la CIA, los espías soviéticos de la KGB, } \\
\text { los chinos o los cubanos. }\end{array}$ \\
\hline
\end{tabular}

Fuente: investigación bibliográfica del autor.

Presidencial (EMP) de Adolfo López Mateos, y dos años después, en 1958, fue designado ayudante militar de la Secretaría de Gobernación, ${ }^{12}$ en donde asistió al licenciado Gustavo Díaz Ordaz en el palacio de Bucareli.

El ministro Díaz Ordaz desactivó las protestas y reclamos del sector obrero y campesino que se gestaron durante el gobierno de Adolfo Ruiz Cortines ${ }^{13}$ aplicando la receta de un macartismo

12 "Hoja de servicio de Luis Gutiérrez Oropeza" en "Gutiérrez Oropeza, Luis, versión pública IPS", en Archivo General de la Nación (en adelante AGN), fondo gobernación, sección DFs, caja 238, exp. único, f. 1.

${ }^{13}$ En 1959 centenares de obreros e intelectuales abarrotaron la cárcel de Lecumberri; fueron detenidos Siqueiros, Filomeno Mata, Chon Pérez, Hilario Moreno, Lumbreras, Encinas, también los ferrocarrileros Valentín Campa y Demetrio Vallejo. En marzo de 1962 fue dictada sentencia de ocho años a David Alfaro Siqueiros y Filomeno Mata, 
criollo. ${ }^{14}$ Durante los seis años como secretario de Gobernación, Díaz Ordaz demostró "inclinación desmesurada por las soluciones violentas y un desprecio visible por la oposición". ${ }^{15}$ Sostuvo un férreo control de la oposición impidiendo manifestaciones y encarcelando a la disidencia obrera de 1958-1959. En junio de 1962 cuando John F. Kennedy visitó la Ciudad de México, Díaz Ordaz mando efectuar razias entre los opositores del régimen, para evitar probables desordenes, la vigilancia policiaca acorraló las protestas y las confinó a la zona de la Ciudad Universitaria. ${ }^{16}$

La cercanía entre ambos paisanos fraguó una amistad sólida que se nutrió desde los años en que convivían en Bucareli, pero especialmente durante la intensa campaña presidencial de 1964. Gutiérrez Oropeza ocupó el cargo de jefe de seguridad del candidato. Durante el recorrido de la geografía nacional, la cercanía se fue convirtiendo en confianza, sobre todo al calor de los actos violentos de provocación terrorista con que sus enemigos políticos del Frente Electoral del Pueblo (FEP), del Movimiento de Liberación Nacional (MLN) y del Partido Comunista Mexicano (PGM) trataron de empañar su campaña. En 1964 la Procuraduría General de Justicia habló de que "existe un Plan preconcebido de agitación"17 en contra del candidato presidencial del PRI.

las pruebas de la acusación fueron endebles. Todo se reducía a que Siqueiros había criticado y desmentido al presidente López Mateos en una gira por el extranjero. Sin autor, "Sentencia Política", Política, 15 de marzo de 1962, pp. 8-12. En agosto de 1963 fueron sentenciados los integrantes del sindicato ferrocarrilero a un total de dos siglos de cárcel. Sin autor, "Dos siglos de prisión", Política, 15 de agosto de 1963, p. 6.

14 "Macartismo criollo" como la caricatura política de 1962 que denunciaba el espionaje y persecución existente en México. Sin autor, "Macartismo criollo", Política, 15 de febrero de 1962, p. 23.

${ }^{15}$ Semo, México un pueblo en la historia, p. 92.

${ }^{16}$ Sin autor, "La décima entrevista", Política, 10 de julio de 1962, p. 7.

17 "Procuraduría General de Justicia", Chihuahua, 23 de abril de 1964, AGN, fondo gobernación, sección DGIPS, caja 2949-A, exp. 31, f. s/n. 
En abril de 1964 durante una visita a la ciudad de Chihuahua, hubo un incidente violento en el mitin en la plaza de armas, "que culminó en el incendio de la tribuna y se propagó a las puertas y ventanas de Palacio Municipal y a un balcón del Banco Nacional de México". ${ }^{18}$ Los inconformes miembros del FEP y estudiantes normalistas increparon al candidato del PRI en el hotel donde se hospedaba, éste salió:

...cruzó la calle y se dirigió, seguido solo de su jefe de ayudantes, el teniente coronel Luis Gutiérrez Oropeza, a la plaza principal en busca de los estudiantes quejosos [...] Empero, elementos extraños a los estudiantes pretendieron acallar con gritos la voz del candidato quien agregó, sin perder la serenidad: - En este clima de violencia no es posible tratar nada- Los mismos elementos ajenos a los normalistas comenzaron a lanzar palos, tantos, que el licenciado Díaz Ordaz, en tono de buen humor, dijo, volviéndoles la espalda a los escándalosos: -Vámonos, que aquí está lloviendo mucho... ${ }^{19}$

Gutiérrez Oropeza, recuerda una anécdota de cuando fue designado responsable de la seguridad del nuevo mandatario. El episodio evidencia confianza, cercanía y complicidad, es el lenguaje franco con el que se le habla a los leales.

El 30 de noviembre de 1964, el presidente electo Gustavo Díaz Ordaz le dijo a quien iba a ser su jefe de Estado Mayor Presidencial:

Coronel, quiero leerle la cartilla, y lo mismo haré con las otras personas que forman parte de mi gabinete. Lo he

\footnotetext{
${ }^{18}$ Rogelio Cárdenas, "Escándalo en Chihuahua tras el mitin Priista", Excélsior, 7 de abril de 1964, pp. 1, 9.

${ }^{19}$ Rogelio Cárdenas, "Escándalo en Chihuahua tras el mitin Priista", Excélsior, 7 de abril de 1964, pp. 1, 9.
} 


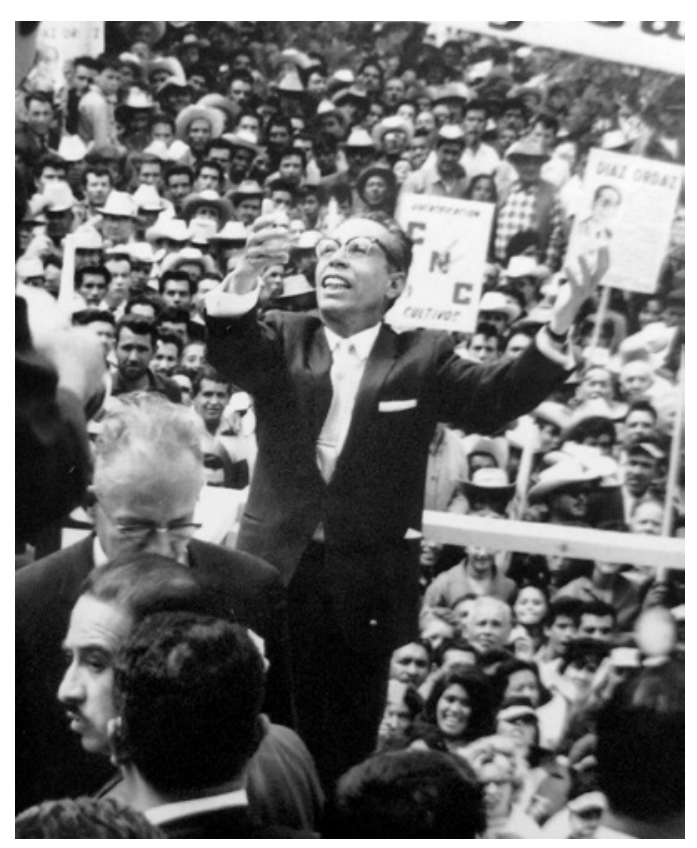

Imagen 4. Campaña electoral, Chihuahua, abril de 1964, Díaz Ordaz y Gutiérrez Oropeza, Archivo General de la Nación, fondo gobernación, sección DGIPs, caja 2949-A, exp. 31.

nombrado a usted mi jefe de Estado Mayor, no por lo que ha trabajado - y vaya que sí ha trabajado-, sino porque me ha sido usted leal y espero que lo siga siendo; de no ser así, pobre de usted y pobre de mí. Pobre de usted, porque yo como presidente lo desbarato y pobre de mí porque muy triste me será el que mi jefe de Estado Mayor sea desleal. Ahora yo les estoy haciendo el honor de designarlos mis colaboradores [se refiere a su gabinete], [pero] dentro de un año considerarán que me están haciendo el favor de ayudarme. ${ }^{20}$

${ }^{20}$ Gutiérrez Oropeza, Gustavo Díaz Ordaz, p. 24. 
Llegado Díaz Ordaz a la Presidencia, el 1 de diciembre de 1964, el poblano es nombrado jefe del EMP, cargo que le permitió establecer una cercanía sin igual. El jefe del EMP es el militar, antes del secretario de la Defensa, que está más cerca del presidente. Ningún otro integrante del gabinete fue tan influyente; entre los militares se dice que ese cargo es más político que militar. ${ }^{21} \mathrm{Y}$ así quedó de manifiesto en las primeras planas del 2 de diciembre de 1964 que publicaron los nombres de los integrantes del gabinete. El nombre del poblano aparece debajo del secretario particular del presidente. ${ }^{22}$

Nuevos estudios en torno al papel jugado por los militares durante el conflicto estudiantil, han demostrado que esa cercanía, no fue del todo positiva, sobre todo por el espíritu perverso de Gutiérrez Oropeza. ${ }^{23}$ Algo sabía Díaz Ordaz de lo tendencioso de su jefe del Estado Mayor, cuando en aquella leida de cartilla, le advierte a Gutiérrez Oropeza: "Los informes démelos en su medida y con oportunidad y tenga mucho cuidado de no 'picarme la cresta', porque mis decisiones equivocadas podrían tener graves consecuencias". ${ }^{24}$

En marzo de 1968 en los pasillos de la Secretaría de la Defensa (SDN) se percibía que al presidente ya le habían "picado la cresta". Desde el arribo de Gutiérrez Oropeza a la jefatura del EMP hubo desconfianza por tan estrecha relación. La opinión generalizada entre los militares, respecto a Gutiérrez Oropeza, era la de un arribista, ${ }^{25}$ un militar "abrepuertas", ${ }^{26}$ que alimentaba un "estado de miedo" permanente y solía ver problemas donde no los había. En un documento anónimo que circuló en los pasillos de la SDN, dirigido al

${ }^{21}$ Entrevista con el mayor Francisco García, 10 de septiembre de 1998, p. 13.

${ }^{22}$ Sin autor, "El Nuevo Gabinete", La Prensa, 3 de diciembre de 1964, pp. 1 y 10.

${ }^{23}$ Veledíaz, Finetes de Tlatelolco, pp. 120-121.

${ }^{24}$ Gutiérrez Oropeza, Gustavo Diaz Ordaz, p. 25.

${ }^{25}$ Luis Gutiérrez Oropeza tuvo un ascenso poco común en el mundo militar, en 1961 cuando se desempeña como ayudante del secretario de Gobernación poseía el grado de mayor. En 1962 recibe el de teniente, en 1964 el de coronel y para 1970 el de general brigadier. Una carrera rápida que fue percibida como la de un arribista. ${ }^{26}$ Veledíaz, Finetes de Tlatelolco, p. 121. 
presidente Díaz Ordaz y a los periódicos capitalinos, se le advertía al presidente: "Parece que Oropeza quiere a toda costa mantener en usted, el complejo de miedo que no creemos que usted lo tenga, porque además no existe razón alguna [para tenerlo]". ${ }^{27}$

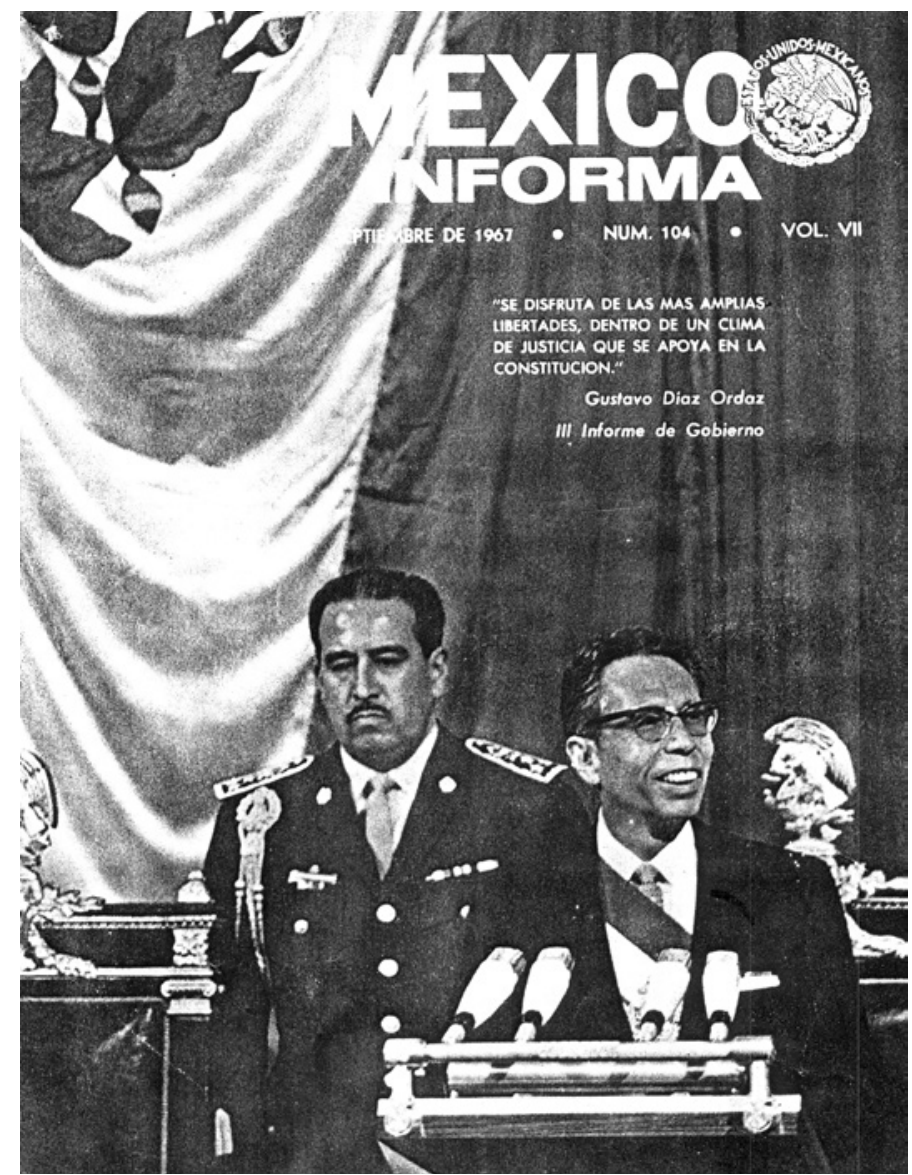

Imagen 5. México informa, núm. 104 (septiembre de 1967), p. 1, Archivo General de la Nación, fondo gobernación, sección DGIPS, caja 2954, exp. EMP.

27 "[Carta anónima al presidente de la República GDO]", Ciudad de México, 1 de marzo de 1968, AGN, fondo gobernación, sección DGIPS, caja 517. 


\section{Francotiradores del EMP en Tlatelolco}

El poblano se destacó por la utilización de métodos violentos para contener protestas. A través del uso de la fuerza, sofocó manifestaciones y desactivó movimientos opositores. No siempre lo hizo de manera legal, pero siempre mostró cierta efectividad. ${ }^{28}$ En el Archivo General de la Nación (AGN) quedó una copia del manual de contención policial de disturbios civiles que entregó al presidente Díaz Ordaz, titulado "Guía para el planeo, adiestramiento y operaciones de fuerzas de policía en la supresión de disturbios civiles". La Dirección Federal de Seguridad (DFS) envió copia el 17 de julio de 1969 y recomendó: "que pudiera ser empleado, si usted lo cree conveniente, en los estados". 29

Otra evidencia del uso ilegal de la fuerza se encuentra contenida en una declaración en la que aceptó ser el artífice de la formación de un grupo paramilitar dedicado a la vigilancia y protección de las instalaciones del Sistema de Transporte Colectivo Metro y de la

${ }^{28}$ Gutiérrez Oropeza "Se vanagloriaba de haber tomado medidas sin que lo supiera el presidente, tales como tener a la mano gente comprada para golpear algunos muchachos en la noche, y cosas así, medidas que tomaban para tranquilidad del presidente". Gilberto Guevara Niebla, "1968: los verdaderos asesinos”, El Universal, 29 de junio de 1999, p. 7.

${ }^{29}$ En el plan de operaciones dice el manual, "b. Al dispersarse una turba, se aplican tales de los siguientes pasos como se juzgue convenientes: (1) Demostración de fuerza. (2) Uso de formación para controlar motines. (3) Uso de agentes químicos. (4) Fuego por tiradores seleccionados. (5) Uso de toda la potencia de fuego.", p. 7. La fuerza debe usarse de manera gradual, pero cuando ocurre el uso de fuego por tiradores, se establece: "k. Se colocan tiradores en posiciones ventajosas donde tengan buenos campos de tiro. Estos deben estar equipados con radios o con otros medios de comunicación para poder someter informes al comandante y recibir órdenes de éste. Cuando se colocan policías sobre los techos y en otras posiciones ventajosas principalmente para observación, se debe brindar protección adecuada". "Guía para el planeo, adestramiento y operaciones de fuerzas de policía en la supresión de disturbios civiles", AGN, fondo gobernación, sección DGIPS, caja 2956, f. 8. 
infraestructura eléctrica e hidráulica de la Ciudad de México. El grupo inicialmente fue denominado Zorro y posteriormente devendría en el grupo paramilitar Los Halcones. ${ }^{30}$ En 2001, Gutiérrez Oropeza aceptó haberle propuesto a Díaz Ordaz la "creación de un cuerpo paramilitar para que se respondiera a los problemas por presentarse". ${ }^{31}$ Como parte de la cúpula en el gobierno perteneció al círculo cercano de Winston Scott, jefe de la estación de la ciA en la Ciudad de México, Gutiérrez Oropeza “[era] ocasionalmente invitado a cenar en su casa [de las Lomas]. Tal vez era un agente LITEMPO", señala el biógrafo de Winston. ${ }^{32}$

Oficialmente, el 2 de octubre de 1968 se desarrollarían dos operaciones militares en Tlatelolco para detener a los miembros del Consejo Nacional de Huelga (CNH) y una más dentro de la República para contener cualquier brote de inconformidad o arribo de contingentes estudiantiles a la Ciudad de México. ${ }^{33}$

Regresemos ahora a las operaciones para detener a los dirigentes del CNH. La primera denominada operación Galeana fue encabezada por el general Crisóforo Mazón Pineda. Su tarea consistía en efectuar

${ }^{30}$ Veledíaz, Finetes de Tlatelolco, pp. 162-164.

${ }^{31}$ Jorge Alejandro Medellín, "Historia oficial en voz del responsable", El Universal, 10 de junio de 2001, p. A6.

${ }^{32}$ La operación LITEMPO, iniciada en 1960, consistió en la colaboración de funcionarios del gobierno mexicano y de los servicios de inteligencia con la estación de la CIA en México, y especialmente con su jefe Winston Scott. Gracias a la cia obtuvo información delicada y confidencial necesaria para identificar potenciales problemas al gobierno norteamericano. En la nómina de LITEMPO estuvieron los presidentes López Mateos Litempo-1, Gustavo Díaz Ordaz Litempo-2, Fernando Gutiérrez Barrios (DFS) LITEMPO-4, Luis Echeverría Álvarez LITEMPO-14. Como parte de la operación, la CIA formuló una red telefónica especial para el presidente, independiente de la red telefónica presidencial. Se espiaban las embajadas de los países socialistas, el tráfico de pasajeros a Cuba, quienes eran interrogados y fotografiados, así como a opositores del régimen. Sobre la relación de Oropeza con Winston Scott, véase: Morley, Nuestro hombre en México, p. 356.

33 Aguayo, De Tlatelolco a Ayotzinapa, p. 94. 
una acción envolvente, que cerraría los accesos a la plaza y empujaría a los asistentes hacia un embudo, en donde serían seleccionados los asistentes para capturar a los líderes y dejar libres a los curiosos. La segunda operación, encabezada por el Batallón Olimpia,$^{34}$ debía cerrar los accesos del edificio Chihuahua de Tlatelolco para evitar que los líderes e integrantes del CNH que permanecerían en el tercer piso huyeran. Ambas operaciones se pusieron en marcha, con la aparición de luces de bengala en el cielo. ${ }^{35}$ La corresponsal italiana Oriana Fallaci asoció las bengalas como la "señal del lugar donde [había] que atacar", ${ }^{36}$ y no estuvo equivocada. ${ }^{37}$

Sin embargo, esas operaciones no eran las únicas que se tenían previstas, hubo una más, secreta, incluso para el secretario de la

${ }^{34}$ Suele confundirse al Batallón Olimpia con el destacamento militar Olimpiaco. El primero fue el grupo de militares y agentes de distintas corporaciones que estuvieron presentes durante la toma del Instituto Politécnico Nacional los días 23 y 24 de septiembre, y el 2 de octubre en la Plaza de las Tres Culturas de Tlatelolco (Véase el documental de Carlos Mendoza, "Tlatelolco: las claves de la masacre") más que ser un batallón militar fueron agentes de la DFS, del Servicio Secreto de la Policía del DDF y de la Judicial que actuaron como grupo paramilitar durante la provocación de Tlatelolco. El Destacamento Militar Olímpico fue el organismo creado por el gobierno federal en octubre de 1966 para coordinar los trabajos entre la SDN y el Comité Organizador, también fue responsable de la seguridad en las instalaciones deportivas y de la protección de atletas y funcionarios. Comité Organizador de los XIX Juegos Olímpicos, Carta olímpica 32: destacamento militar olímpico.

35 Aguayo, De Tlatelolco a Ayotzinapa, p. 93.

${ }^{36}$ López, "El grito".

${ }^{37}$ El relato de Fallaci, se volvió sumamente popular en todo el mundo, fue una estocada a la versión oficial. Oriana Fallaci estuvo en el tercer piso del edificio Chihuahua y fue herida por dos proyectiles en pierna y glúteo, su texto "The shooting of Oriana Fallaci”, publicado el 30 de octubre en la revista Look, causó estupor al Servicio Exterior Mexicano. El embajador en EU, Hugo Margáin, en telegrama al secretario de Relaciones Exteriores, comenta sobre el texto de Fallaci: "La difusión de este tipo de informaciones sigue causando daño". Hugo B. Margáin a Antonio Carrillo Olea, 30 de octubre de 1968, Archivo Histórico Genaro Estrada de la Secretaría de Relaciones Exteriores (en adelante AHSRE), fondo movimiento estudiantil de 1968 . 
Defensa (Marcelino García Barragán), que consistió en abrir fuego contra la multitud, sin distinción entre estudiantes, vecinos y militares. Por lo menos diez francotiradores entrenados en el EMP fungieron como provocadores, y fueron secundados por elementos paramilitares que dijeron pertenecer al Batallón Olimpia los cuales accionaron sus armas desde el tercer piso del edificio Chihuahua contra la multitud. ${ }^{38}$ De acuerdo con Carlos Montemayor, el inicio de la balacera sucedió con el disparo que impactó al general José Hernández Toledo, ${ }^{39}$ el proyectil que hirió al militar provino del techo del templo de Santiago de Tlatelolco, el francotirador, probablemente del EMP, lo observó con la mira telescópica acercarse desde san Juan de Letrán, cruzar las ruinas tlatelolcas y arribar a la plaza por el costado de la Vocacional 7 empuñando un altavoz.

Esta operación se planeó en la alta jerarquía del país, concediendo que García Barragán no sabía nada, como lo consignó en sus apuntes, que posteriormente fueron incorporados al libro Parte de guerra. La provocación fue orquestada entre los poblanos, en una explosiva mezcla de lealtad y complicidad y fue organizada por Gutiérrez Oropeza y comandada por el teniente coronel Carlos Humberto Bermúdez Dávila (jefe de la sección segunda del EMP) quien coordinó con antelación el abastecimiento de armas y municiones a "grupos paramilitares que estaban esparcidos entre los muchos empleados del entonces DDF [en Tlatelolco]". ${ }^{40}$ El poblano fue el responsable de la provocación, según García Barragán, ubicó los francotiradores en edificios contiguos a la Plaza de las Tres Culturas de Tlatelolco, el 2 de octubre de 1968, que dispararon contra la multitud. García Barragán lo narra de la siguiente manera:

\footnotetext{
38 "Era raro ver eso, como los guantes de gala que usan en los desfiles, pero nada más uno $[\ldots]$ y no todos, había uno que otro con un pañuelo blanco enredado en la mano $[\ldots]$ que vi a uno de ellos sacar una enorme pistola y comenzar a disparar sobre la plaza, al azar, sin apuntar..." González de Alba, Otros días, otros años, p. 103. ${ }^{39}$ Montemayor, La violencia de Estado, p. 125.

${ }^{40}$ Carrillo Olea, México en riesgo, p. 43.
} 
Como a las 7:30 de la noche me habló el general Mazón, para pedir permiso para registrar los edificios donde había francotiradores, lo autoricé y como a los 15 minutos me habló el general Oropeza.

"Mi general", me dijo: Tengo varios oficiales del Estado Mayor Presidencial apostados en algunos departamentos, armados con metralletas para ayudar al ejército con órdenes de disparar a los estudiantes armados, ya todos abandonaron los edificios, solo me quedan dos que no alcanzaron a salir y la tropa ya va subiendo y como van registrando los cuartos temo que los vayan a matar, ¿quiere usted ordenar al general Mazón que los respete? General Barragán:

—En estos momentos hablo con el general Mazón, como me lo pides.

Hablé con el general Mazón trasmitiendo la petición del general Oropeza.

General Mazón:

- Sí mi general ya tenemos uno armado con metralleta y dice haber disparado hacia abajo.

$\mathrm{Al}$ poco rato me habló Mazón para informarme que ya se había presentado el otro oficial, también armando con metralletas y que había hecho lo mismo.

Enseguida me comuniqué con Oropeza, informándole que ya habían aparecido los dos oficiales y ya se les había ordenado se incorporaran al Estado Mayor Presidencial. ${ }^{41}$

Marcelino García Barragán tuvo que atar los cabos para entender lo sucedido aquella tarde, y no fue fácil, sobre todo porque "El poblano

${ }^{41}$ Scherer y Monsiváis, Parte de guerra, pp. 50-51. 


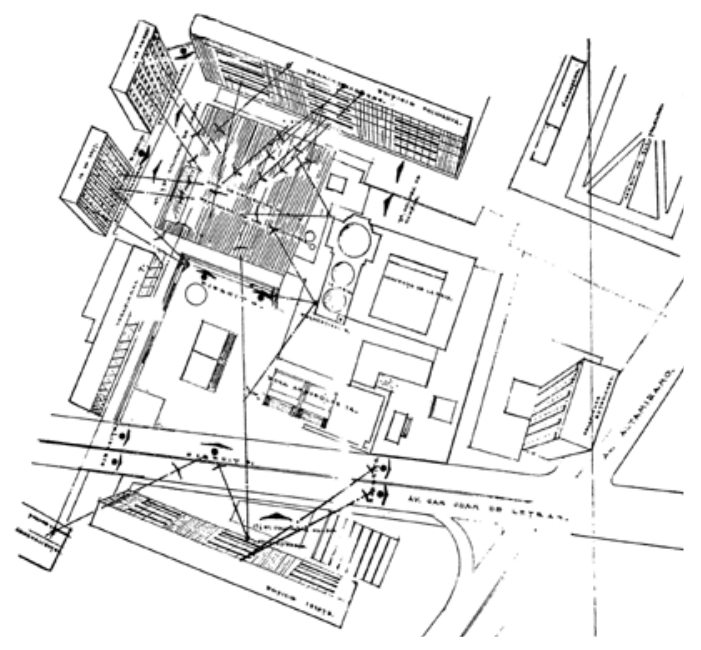

Imagen 6. "Croquis con ubicación de origen de disparos, en informe Tlatelolco PGR", octubre de 1968, Archivo General de la Nación, sección gobernación, fondo DGIPS, caja 2866.

ordenó destruir documentación relacionada con la matanza del 2 de octubre". ${ }^{42}$ El general secretario cargaba con el estigma y la responsabilidad; por eso en 1976 reclamó al ex regente del Distrito Federal (19641970) general y licenciado Alfonso Corona del Rosal, seguir repitiendo la versión de que grupos estudiantiles dispararon a discreción y que provocaron la masacre en la Plaza de las Tres Culturas. El intercambio epistolar entre los dos militares se cierra con la sentencia de García Barragán: "Deduzco que aún consideras prematuro que la Nación conozca la verdad de ese episodio que todos lamentamos". ${ }^{43}$ Para García Barragán, era claro que Gutiérrez Oropeza "había estado dando contraórdenes o fallado en la interpretación correcta de sus órdenes”"\$4 durante 1968.

${ }^{42}$ Veledíaz, Finetes de Tlatelolco, p. 161.

${ }^{43}$ Scherer y Monsiváis, Parte de guerra, pp. 25-26 y sin autor, "De García Barragán a Corona del Rosal: 'Deduzco que aún consideras prematuro que la Nación conozca la verdad...", Proceso, 17 de septiembre de 1995, p. 31.

${ }^{44}$ Pascal Beltrán del Río, "Versión de la inteligencia militar de Eu: La indisciplina de los dos generales provocó la matanza de Tlatelolco", en Proceso, número 1091, 28 de septiembre de 1997, p. 7. 


\section{Violencia autorizada}

Gutiérrez Oropeza acostumbrado al uso de violencia y partidario de conjeturar enemigos ficticios, hizo traer un grupo de especialistas en explosivos estadounidenses, que instruyeron a paramilitares mexicanos en la elaboración, manejo y uso de los mismos. ${ }^{45}$ Durante el invierno de 1968 sucedieron una serie de atentados que estremecieron diversos puntos de la Ciudad de México y Guadalajara. ${ }^{46}$

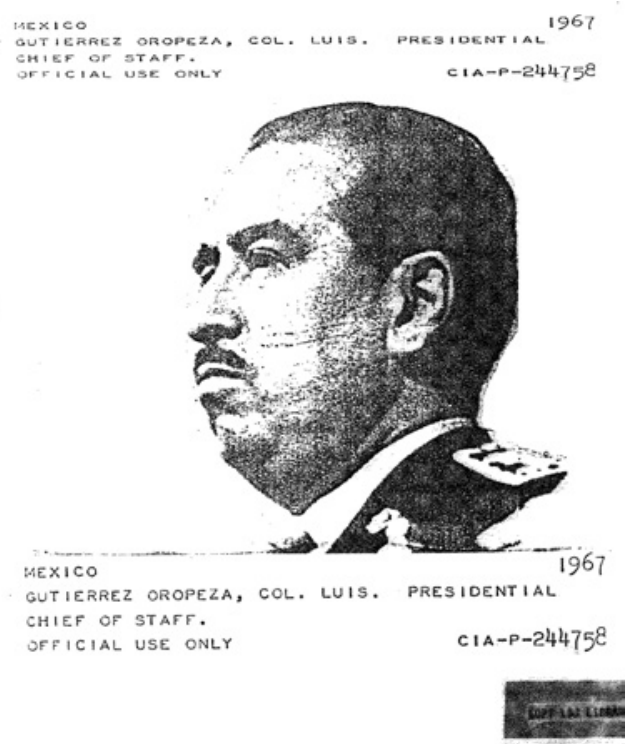

Imagen 7. Ficha de Luis Gutiérrez Oropeza en expediente de la CIA sobre funcionarios del gobierno de Gustavo Díaz Ordaz, 1967, Lyndon Baines Johnson Library.

${ }^{45}$ Scherer y Monsiváis, Parte de guerra, p. 53.

${ }^{46}$ En diciembre de 1968 sucedieron cuatro atentados con bombas caseras. El 14 de diciembre de 1968 fue el primero, en el edificio del Comité Nacional del PRI. El 15 de diciembre de 1968, tres más, al juzgado xv mixto de paz de la delegación Iztacalco, el edificio de la Confederación de Trabajadores de México y en la sala de espera de la central camionera de Guadalajara. "Informe DFs 15-XII68", "Informe DFs 14-XII-68" y "DFs Informe CTM, 15 de diciembre 1968", AGN, fondo gobernación, sección DGIPS, caja 2959. 
Y que muchos de ellos fueron adjudicados a estudiantes resentidos. $^{47}$

Del mismo modo, Gutiérrez Oropeza fue señalado por Cuauhtémoc Cárdenas como responsable del sabotaje al avión que trasladaba al licenciado Carlos A. Madrazo a la ciudad de Monterrey, y que le costó la vida en junio de 1969. Para el hijo del presidente Cárdenas, el sabotaje, fue "preparado y mandado por Gutiérrez Oropeza, quien era dado al uso de la violencia y el presidente se lo permitía". ${ }^{8}$

Gutiérrez Oropeza tomó a la letra el permiso que Díaz Ordaz le había ofrecido desde aquella leida de cartilla de 1964:

\begin{abstract}
Coronel, si en el desempeño de sus funciones tiene que violar la Constitución no me lo consulte porque yo, el presidente, nunca le autorizaré que la viole; pero si se trata de la seguridad de México o de la vida de mis familiares, Coronel, viólela, pero donde yo me entere, yo el presidente, lo corro y lo proceso, pero su amigo Gustavo Díaz Ordaz le vivirá agradecido. ${ }^{49}$
\end{abstract}

De acuerdo con documentos de la inteligencia militar de los Estados Unidos de Norteamérica, luego de los acontecimientos de 1968, Luis Gutiérrez Oropeza dejó de ser del agrado del secretario de la Defensa, general García Barragán, quien empezó a relegarlo, asegurándose que dejara de aparecer en todos los actos detrás del presidente. Así, conforme se acercó el fin del sexenio fue disminuyendo su poder y presencia. Durante el día del ejército, el 19 de febrero de 1969, “un joven capitán del ejército se paró directamente detrás del presidente,

\footnotetext{
${ }^{47}$ Una denuncia ciudadana del 16 de diciembre de 1968 dice: "El atentado al PRI es obra de Cruz Lemus, de los mismos que tuvieron mucho que ver con la balacera en Tlatelolco y que están metidos hasta las manitas en el movimiento estudiantil, solo que son muy discretos y saben disimular". "Informe DFs 16-XII-68, AGN, fondo gobernación, sección DGIPS, caja 2959.

${ }^{48}$ Cárdenas, Sobre mis pasos, México, p. 95.

${ }^{49}$ Gutiérrez Oropeza, Gustavo Diaz Ordaz, p. 25.
} 


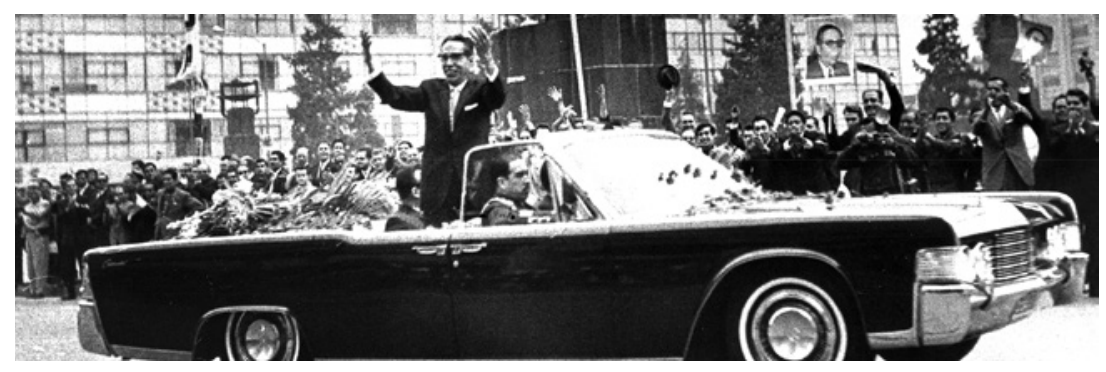

Imagen 8. "Escolta presidencial", Archivo General de la Nación, fondo Díaz Delgado y García, exp. L99466, L99471.

mientras Gutiérrez estaba sentado en una mesa [contigua]", ${ }^{50}$ entonces dejó de tener el lugar privilegiado, siempre junto al presidente, con la posibilidad de susurrarle al oído, como si se le quisiera relegar.

La fama como recio inquisidor y defensor del régimen mexicano, que aplastaba a los adversarios, traspasó la esfera militar y a pesar del malestar en su contra por la manera en que actuó durante el conflicto de 1968 obtuvo reconocimiento de pobladores que lo veían como un esforzado perseguidor de agitadores y comunistas. En abril de 1970, a poco tiempo de la conclusión del sexenio y de que se extinguiera su buena estrella, recibió una carta muy significativa. El comisionado Ejidal y la Junta de Mejoras Materiales de san Jerónimo Aculco Lídice en el D.F., le hicieron saber de "las actividades de un grupo de personas en este ejido [...] han estado pegando en postes y paredes unos volantes en los que se está agitando a los colonos y se denigra a los representantes de la colonia [...] buscan agitar a gente pacífica". Por tal motivo piden al general "su valiosa intervención, para exterminar a esta clase de alimañas, que, a todas luces, trata de agitar y tener en zozobra a la gente pacífica, con sus falsedades". ${ }^{51}$

${ }^{50}$ Veledíaz, Los jinetes de Tlatelolco, p. 155.

51 "Carta del comisario Ejidal y la Junta de Mejoras Materiales de San Jerónimo Aculco Lídice D.F. al señor general don Luis Gutiérrez Oropeza”, Distrito Federal, 9 de abril de 1970, en Gutiérrez Oropeza, Luis, versión pública DFs, AGN, fondo gobernación, sección DFs, caja 238, ff. 11 y 12. 
Luego del traspaso de poderes, y de la asunción de Luis Echeverría como presidente de la República, ${ }^{52}$ el poblano fue nombrado, el 1 de diciembre de 1970, director general del Departamento de Industria Militar, ${ }^{53}$ en donde se desempeñó de manera adecuada. El 13 de octubre de 1972, los trabajadores de la fábrica de armas, miembros del Sindicato de Trabajadores de las Industrias Militares efectuaron un paro de labores entre las 10:00 a las 10:10 horas como protesta por una justa retabulación de salarios de "todos los trabajadores del gremio". El paro duró tan poco por la "pronta intervención del general Gutiérrez Oropeza, los trabajadores depusieron su actitud y reanudaron sus labores", luego de que el poblano se comprometiera a resolver el asunto personalmente "antes del pago de sus aguinaldos". ${ }^{44}$ Su paso por las Industrias Militares finalizó el 1 de julio de 1973 a causa de intrigas políticas entre la clase militar:

\begin{abstract}
No duró mucho [en el puesto], una serie de anónimos que comenzaron a correr en las instalaciones de la Secretaría de la Defensa, en los que se mofaban del grupo de generales, muchos de ellos con edad promedio de más de 70 años, que habían copado los cargos más importantes nombrados por el nuevo secretario de la Defensa, el general Hermenegildo Cuenca, apuntaban a su oficina como origen. Aquel grupo de ancianos se les bautizó como la momiza. ${ }^{55}$
\end{abstract}

El secretario de la Defensa del sexenio 1970-1976, detestó a Gutiérrez Oropeza por los señalamientos que pesaban en su contra por los

52 "Hoja de Servicio de Luis Gutiérrez Oropeza", en "Gutiérrez Oropeza, Luis, versión pública IPS", AGN, fondo gobernación, sección DFS, caja 238, exp. único, f. 1. ${ }^{53}$ Sin autor, "General Luis Gutiérrez Oropeza, jefe del Departamento de la Industria Militar", en El Día, 2 de diciembre de 1970, p. 3.

54 "Informe DFs del 13 de octubre de 1972. Asunto: Sindicato de Trabajadores de la Industria Militar", Distrito Federal, en Gutiérrez Oropeza, Luis, versión pública DFs, AGN, fondo gobernación, sección DFs, caja 238, f. 21.

${ }^{55}$ Veledíaz, Juan, "Tres momentos desconocidos del 2 de octubre del 68", Estado Mayor.mx, http://rewrerestadomayor.mx/33870 [consultado el 26 de mayo de 2018]. 
acontecimientos del 2 de octubre y por el tema de unos anónimos que en los pasillos de la SDN fueron soltados, para desprestigiar al nuevo jefe del EMP. Para mantenerlo fuera del círculo militar cercano al presidente Echeverría Álvarez fue promovido como embajador en Portugal del año 1973 a 1974. A su regreso, solicitó incorporarse como agregado militar del Estado Mayor Presidencial.

[Hermenegildo] Cuenca mandó que lo enviaran de comandante de la guarnición militar de Manzanillo, en Colima. Era un cambio drástico, de una embajada en Europa, a un cuartel en el Pacífico mexicano. El poblano se inconformó, no quería ir y no tardó en ser llamado a la oficina del general Cuenca. Ahí, frente a frente, un par de ayudantes del secretario presenciaron esta escena entre los dos generales. - Tiene usted tres opciones: cumplir con la orden, no cumplir, pero si no cumple por evidencia lo proceso; o pida su retiro. ¿Qué escoge?, le cuestionó Cuenca.

-Pues me retiro, dijo Gutiérrez Oropeza. Y se retiró del ejército como general de brigada. ${ }^{56}$

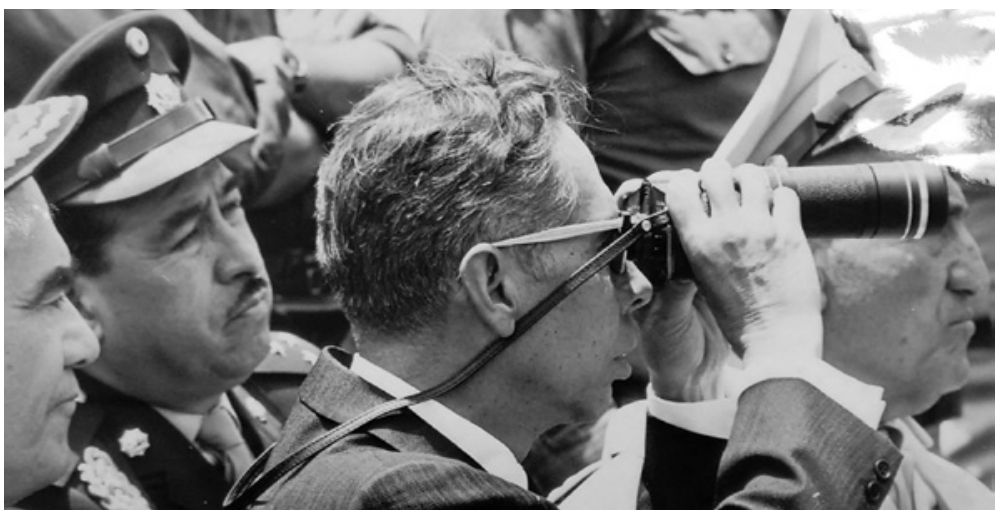

Imagen 9. "Presenciando ensayos militares, 1969", Archivo General de la Nación, fondo Presidente Gustavo Díaz Ordaz, 122/2.

${ }^{56}$ Veledíaz, "Tres momentos desconocidos del 2 de octubre del 68", Estado Mayor.mx, http://wrew.estadomayor.mx/33870 [consultado el 26 de mayo de 2018]. 


\section{Dos de octubre, se solicitan mártires}

De acuerdo con Gutiérrez Oropeza, y como ya se vio con los exponentes de la historiografía militar, el movimiento estudiantil había ya decidido dar el golpe de timón, y encarar al gobierno mexicano para despojarlo de la conducción del país; en su obra La realidad de los acontecimientos... dice que la violencia desatada desde el 23 de septiembre y que desembocaba en el 2 de octubre formaba parte de un plan maestro de desestabilización.

La conspiración internacional determinó el 15 de septiembre, luego de la fiesta mexicana en Ciudad Universitaria, que formarían una "Junta de Gobierno, que en la primera oportunidad pediría fuera reconocida por los países socialistas y comunistas". ${ }^{57}$ La estrategia militar del movimiento, según Gutiérrez Oropeza, contemplaba "apoderarse del edificio de Relaciones Exteriores", 58 para convertir el recinto en "su cuartel general". ${ }^{59}$ Y luego de la provocación de Tlatelolco, se creía que comandos militares extranjeros intervendrían en México "con el pretexto de proteger y desalojar a sus delegaciones deportivas y que ya se encontraban en el país". ${ }^{60}$

Veamos cómo describe el desarrollo de los acontecimientos del 2 de octubre que tuvieron el fin de provocar violencia para desembocar inercias incontenibles de acuerdo con un plan perverso correspondiente con "una franca operación de guerrilla urbana". Oropeza dice que el movimiento estudiantil estaba decayendo, que ya no convocaba gente y que tuvieron que llevarla de mercados populares en barrios pobres a las que pagaron 50 pesos, a las "señoras se les rogó que llevaran

${ }^{57}$ Petrich Blanche y Triunfo Elizalde, "Gutiérrez Oropeza debe probar sus palabras, dice Álvarez Garín”, La fornada, 17 de julio de 1997, p. 13.

${ }^{58}$ Petrich Blanche y Triunfo Elizalde, "Gutiérrez Oropeza debe probar sus palabras, dice Álvarez Garín”, La Fornada, 17 de julio de 1997, p. 13.

${ }^{59}$ Petrich Blanche y Triunfo Elizalde, "Gutiérrez Oropeza debe probar sus palabras, dice Álvarez Garín”, La Fornada, 17 de julio de 1997, p. 13.

${ }^{60}$ Petrich Blanche y Triunfo Elizalde, "Gutiérrez Oropeza debe probar sus palabras, dice Álvarez Garín”, La fornada, 17 de julio de 1997, p. 13. 
niños". ${ }^{61}$ Unas horas antes, estudiantes y "sujetos de barbas sucias y de hablar extraño" ocuparon posiciones estratégicas en ventanas y azoteas de edificios que daban a la plaza. "Estaban armados con metralletas, ametralladoras, rifles de largo alcance y mira telescópica, escuadras, pistolas y cartuchos de dinamita". A las 5:30 dio inicio el mitin "con un discurso violento en extremo". Dos helicópteros volaban sobre la unidad de multifamiliares, se pudo ver a "Mario Menéndez Rodríguez director de la revista $i P o r q u e ́$ ?, acompañado por el rubio yanqui Terry Cory, agente de la cis". Terry usaba un walkie talkie y en dos ocasiones "sacó gruesos fajos de dinero", que entregó a Menéndez, "quien desaparecía por entre los pasillos". ${ }^{2}$ A las 6:05 arribaron los elementos militares encabezados por el general José Hernández Toledo "que trataba de hablar con los del CNH para convencerlos de no tratar de retomar las instalaciones del IPN en Santo Tomás". De repente Terry dio una instrucción y "unos segundos después una carga de ametralladora derribó al general Hernández Toledo, quien arrojaba sangre por la boca". Otro individuo desde el balcón del tercer piso del edificio Chihuahua "comenzó a disparar contra las mujeres, niños, estudiantes, obreros y vecinos, que ocupaban la plaza". Unos cohetes de "bengala - ahora de color rojo - indicaron a los tiradores que iniciaran el fuego cerrado con metralletas y cuanto tuvieran a la mano". Cinco minutos después, ya que se había reagrupado la tropa, repelió la agresión, abrió "fuego contra los embozados en los marcos de las ventanas y en las azoteas; y pronto hicieron blanco entre los francotiradores de los edificios". Un grupo de agentes de la Federal de Seguridad, llegaron al edificio Chihuahua y detuvieron a los oradores "principales cabecillas del movimiento", a las 7 de la noche comenzó a incendiarse parte del edificio por la perforación de los tanques de gas, cuando arribaron los bomberos "trataron de apagar el fuego, y los estudiantes, los recibieron a balazos, impidiendo

${ }^{61}$ Gutiérrez Oropeza, La realidad de los acontecimientos, p. 59. La ubicación de este libro: AGN, fondo Sedena, Sección EMP, caja 147, expediente 25-1967.

${ }^{62}$ Gutiérrez Oropeza, La realidad de los acontecimientos, p. 60. 
el auxilio". Finalmente, en la madrugada del 3 de octubre "quedó dominada la situación. La mayor parte de los agazapados tiradores fueron atrapados o habían huido. El número de muertos era grande, unos 30 entre civiles y militares y más de un centenar de heridos". ${ }^{63}$

En suma, el 2 de octubre las cosas no salieron como lo tenían contemplado las fuerzas conspirativas:

...Fueron los "guerrilleros" quienes dispararon sobre el
pueblo y causaron la atroz matanza. Al gobierno no le
convenía que hubiera muertos. Por eso iba el general
Hernández Toledo a parlamentar. A los únicos que les
interesaba tener cadáveres era a los del cNH para desfi-
larlos en una gigantesca manifestación y acusar al presi-
dente, echándole al pueblo encima. ${ }^{64}$

El acto de inmolación que significó el 2 de octubre se explica a partir de un volante atribuido al CNH y que fue publicado días u horas antes del mitin del 2 de octubre. Nuevamente se encuentra presente el elemento de duda de la autenticidad del volante-proclama titulado "Mexicano" que invita a la reunión en la Plaza de las Tres Culturas, y concluye con la frase: "Todos los hombres han de morir, pero la muerte puede tener distintos significados. CNH". Para Gutiérrez Oropeza está clarísimo y no hay lugar para dudas que los planes de desestabilización en México implicaban sacrificar al movimiento estudiantil, "en dicha proclama abiertamente se incitaba a los asistentes a matar o morir". 65

\section{La realidad de los acontecimientos: la conspiración}

En 1977, cuando se retiró de la actividad castrense Luis Gutiérrez Oropeza tuvo tiempo para escribir dos libros. Ambos son materiales

\footnotetext{
${ }^{63}$ Gutiérrez Oropeza, La realidad de los acontecimientos, p. 62.

${ }^{64}$ Gutiérrez Oropeza, La realidad de los acontecimientos, p. 62.

${ }^{65}$ Gutiérrez Oropeza, La realidad de los acontecimientos, p. 63.
} 
valiosos para el estudio de la historiografía oficialista sobre el movimiento estudiantil de 1968. La primera de sus obras refleja en el título la lealtad a su amigo y paisano: Díaz Ordaz. El hombre. El gobernante, fue publicada en mayo de 1986. El otro, La realidad de los acontecimientos de 1968, publicado en abril de 1996, del que ya se han tomado fragmentos, es una verdadera farsa que busca responsabilizar a todos menos al gobierno en turno, "Díaz Ordaz no cuidó su imagen, para él la Patria estaba primero. Era inmensamente nacionalista". 66

\section{§TODOS LOS HOMBRES HAN DE MORIR, PERO LA MUERTE PUEDE TENER DISTINTOS SIGNIFICADOS $\S$$$
\text { C.N.H. }
$$

Imagen 10. Fragmento de la proclama "Mexicano", atribuida al cNH, Colección CIDOC, Movimiento estudiantil, Tarsicio Ocampo, Biblioteca Daniel Cosío Villegas de El Colegio de México.

Luego de revisar cómo narra lo sucedido en Tlatelolco, y en general el planteamiento sobre el desarrollo del movimiento estudiantil, se puede afirmar que la versión que ofrece Gutiérrez Oropeza no concuerda con el grado de información a que tuvo acceso, y sobre todo desentona con versiones ofrecidas por militares como la de Urrutia o la correspondencia de García Barragán con Corona del Rosal en 1996.

Gutiérrez Oropeza concede importancia a actores detrás de bambalinas y materializa la noción de conjura internacional en una veintena de personajes y un puñado de instituciones. Consigna algunos documentos como fuentes de información que son utilizados de manera tendenciosa, invariablemente para encontrar fundamento a sus afirmaciones. Sin embargo, es confusa y poco creíble la confluencia de

${ }^{66}$ Gutiérrez Oropeza, La realidad de los acontecimientos, p. 68. 
actores antagónicos que buscan un fin común: sabotear los Juegos Olímpicos y desestabilizar al gobierno mexicano.

Un par de sujetos personifican la conjura sobre el gobierno de Díaz Ordaz, son el ex presidente Lázaro Cárdenas y el ingeniero Heberto Castillo Martínez. De acuerdo con Gutiérrez Oropeza, el general Lázaro Cárdenas es el principal cabecilla del movimiento social y lleva décadas haciéndole el juego al comunismo internacional.

Los esfuerzos por desestabilizar el gobierno mexicano iniciaron desde la década de 1950, pero tomaron mayor fuerza luego de que la Revolución cubana se proclamara socialista y con ello se abrió la posibilidad de influir por parte del bloque socialista en el hemisferio americano. En el contexto de agresiones hacia Cuba el general Cárdenas decidió “trasladarse para apoyar 'moralmente' a Fidel Castro", el presidente López Mateos le prohibió salir de país pues era general del ejército mexicano. Entonces "Cárdenas pidió su baja del Ejercito". 67

El general Cárdenas tuvo influencia durante los gobiernos que le siguieron, pero de acuerdo con Oropeza, ante "la imposibilidad de someter a su mando a López Mateos, Cárdenas preparó una insurrección campesina que encabezó Rubén Jaramillo", 68 y como parte del plan fue fundado el MLN, en 1961, inspirado en los logros alcanzados por los movimientos guerrilleros latinoamericanos. Heberto Castillo fue de los fundadores del MLN, luego, en 1963, Castillo asistió a La Habana como representante ante la Conferencia Tricontinental, ahí se discutió la necesidad de expandir a nivel mundial la lucha por la liberación de todos los pueblos, al final se acordó que cada pueblo decidiría los medios a utilizar para obtener su libertad, desde la lucha de masas, la contienda electoral o la lucha armada. En este sentido "Heberto Castillo fue más allá y mucho más alto en la vida pública del país", los integrantes del MLN "recorrieron parte del país y platicaron con grupos de estudiantes y campesinos, buscando ganar

${ }^{67}$ Gutiérrez Oropeza, La realidad de los acontecimientos, p. 15.

${ }^{68}$ Gutiérrez Oropeza, La realidad de los acontecimientos, p. 16. 
adeptos en encubierta agresión al gobierno del presidente Díaz Ordaz [sic]". Como resultado de esta gira "y de los viajes de Heberto a Rusia y Cuba, cayeron en manos de la tendencia comunista" ${ }^{\prime 69}$ una decena de escuelas y universidades que estaban en su regazo. Así, cuando la violencia de los granaderos y los cientos de detenidos, desencadenaron las protestas, Heberto Castillo y un grupo de maestros hacían:

Una labor tesonera y efectiva como una gota de agua que perfora la roca. Usando la imaginación, la fogosidad, el entusiasmo y la candidez de los "líderes" y estudiantes del CNH, con sus cátedras, sus charlas, en conferencias y a través de sus escritos, los convencieron, indujeron y manejaron arrastrándolos en su loca aventura. ${ }^{70}$

El general Cárdenas los apoyó en todo momento, les ofreció recursos y sobre todo protección en los contratiempos, a Heberto Castillo lo escondió en su casa ${ }^{71}$ y a otros maestros y líderes que eran perseguidos por la policía les encontró acomodo. Heberto Castillo fungió como bisagra entre los intereses comunistas y el de los políticos resentidos que financiaban todo el alboroto, "basta con mencionar las reuniones con improvisados líderes estudiantiles y entrevistas privadas de maestros encabezados por Castillo con algunos políticos resentidos y con

${ }^{69}$ Gutiérrez Oropeza, La realidad de los acontecimientos.

${ }^{70}$ Gutiérrez Oropeza, La realidad de los acontecimientos, p. 23.

${ }^{71}$ El miércoles 4 de septiembre de 1968 "fue brutalmente agredido por agentes de la policía federal de seguridad a las 9:30 de la noche, frente a su casa, quienes intentaron secuestrarlo con el posible y siniestro propósito de asesinarlo. Y es que el representante de la Coalición de Maestros nunca se ha apartado de la Constitución Mexicana, la Carta Magna que rechazan algunas y muy acostumbradas autoridades de la nación”. Mario Menéndez Rodríguez, “¡Renuncie!, General”, ¿Por quée, 11 de septiembre de 1968, p. 15. Por suerte lo dejaron golpeado pero vivo entonces el general Lázaro Cárdenas le ofreció resguardo en su domicilio, porque la casa del ingeniero no era segura, ni que anduviera en la calle, le dijo: "Si te agarran te van a matar". 
el general Lázaro Cárdenas". ${ }^{72}$ El 15 de septiembre de 1968 Castillo, acompañado de "los supuestos salvadores de la patria"73 dio el grito de independencia en la explanada de Ciudad Universitaria, Díaz Ordaz lo vivió como otro agravio a los símbolos nacionales y profundizó su rencor hacia Heberto llamándolo "el presidentito". ${ }^{74}$

Según Enrique Krauze, quien tuvo acceso a las memorias inéditas de Gustavo Díaz Ordaz, éste, al igual que Gutiérrez Oropeza percibían a Heberto como el enemigo más importante, la cabeza de la conjura; Díaz Ordaz apuntó que Heberto "llego a consolidarse como la máxima autoridad dentro del CNH y ante los diversos comités de huelga y lucha", ${ }^{75}$ por esa razón el presidente Díaz Ordaz le imputó la ocurrencia de tomar el zócalo y convertirlo en campamento aquella noche del 27 de agosto y obligarlo a renunciar a su cargo, tomado el zócalo y abarrotado por "desaforados, el presidente de la República sentado en el banquillo de los acusados, contestando preguntas y aguantando injurias y burlas. Después vendría la presión física para que firmara algún documento" ${ }^{76}$

Todas las piezas de la conjura están en la mesa, fuerzas superiores, con emisarios hábiles de gran popularidad y masas ingenuas fácilmente moldeables.

En la explicación sobre los actores y fuerzas que participan en la conjura, confluyen distintos actores, muchos de ellos antagónicos entre sí, pero que buscan el mismo objetivo: derrocar el gobierno revolucionario.

${ }^{72}$ Gutiérrez Oropeza, La realidad de los acontecimientos, p. 63.

${ }^{73}$ Gutiérrez Oropeza, La realidad de los acontecimientos, p. 55.

${ }^{74}$ Krauze, La presidencia imperial, p. 367.

${ }^{75}$ Gutiérrez Oropeza, La realidad de los acontecimientos, p. 373.

${ }^{76}$ Gutiérrez Oropeza, La realidad de los acontecimientos, p. 367. 


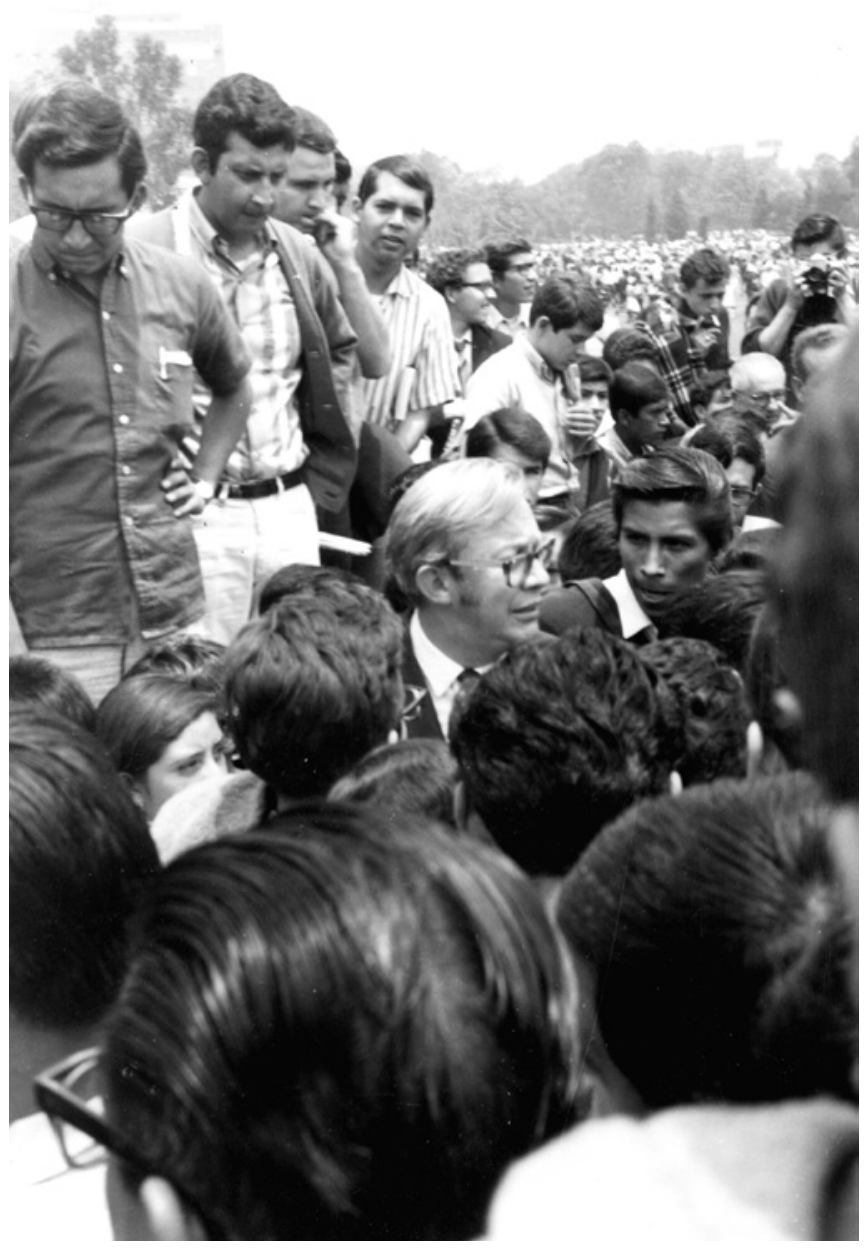

Imagen 11. Heberto Castillo, Marcelino Perelló y Sócrates Campos en la explanada de la rectoría de la Universidad Nacional Autónoma de México, 20 de agosto 1968, El Universal. 
El encapuchado Consejo Nacional de Huelga buscaba derrocar al gobierno de México para colocar tal vez a cualquier súbdito [de] Castro Ruz, Breznev o de Mao, tal vez de la ciA, pues también a lo mejor a un cura de los llamados progresistas — que nada tienen de eso-, infiltrados para continuar su tarea de oscurantismo secular. ${ }^{77}$

Los estudiantes son sujetos manipulados, son "idiotas útiles", los verdaderos sujetos históricos del movimiento estudiantil son otros. En el Cuadro 2 se pueden observar las fuerzas o individuos detrás de la protesta juvenil, nótese la convivencia de fuerzas contrarias apoyando el mismo objetivo, un cuadro perfecto desde una perspectiva esquizofrénica.

${ }^{77}$ Gutiérrez Oropeza, La realidad de los acontecimientos, p. 62. 
Guadro 2. Actores detrás del movimiento estudiantil de 1968.

\begin{tabular}{|c|c|c|}
\hline \multicolumn{3}{|c|}{ Ámbito Internacional } \\
\hline País & $\begin{array}{l}\text { Dependencia o } \\
\text { persona }\end{array}$ & Función \\
\hline $\begin{array}{l}\text { Estados } \\
\text { Unidos de } \\
\text { América }\end{array}$ & $\begin{array}{l}\text { La CIA } \\
\text { El Departamento } \\
\text { de Estado } \\
\text { Embajador } \\
\text { Fulton Freeman }\end{array}$ & $\begin{array}{l}\text { El gobierno mexicano afecta intereses } \\
\text { estadounidenses en la industria petrolera, } \\
\text { además de haber derrotado a Detroit } \\
\text { como sede olímpica, lo cual representó } \\
\text { una pérdida de dinero. } \\
\text { La cia y el Departamento de Estado, } \\
\text { generaron un conflicto que no existía, } \\
\text { llevaron a un grupo de politécnicos para } \\
\text { que pelearan con los estudiantes de la } \\
\text { prepa privada en la Ciudadela el } 23 \text { de } \\
\text { julio de 1968. } \\
\text { El embajador Fulton Freeman, tuvo } \\
\text { reuniones con líderes estudiantiles y maes- } \\
\text { tros universitarios a los que entregó dinero. } \\
\text { El embajador Freeman se reunió con } \\
\text { Humberto Romero, Benito Coquet, } \\
\text { Carlos A. Madrazo, Donato Miranda } \\
\text { Fonseca, Ernesto P. Uruchurtu, Sealtiel } \\
\text { Alatriste y les ofreció restituirles el poder } \\
\text { si apoyaban el movimiento estudiantil. } \\
\text { La embajada de EUA obsequió al movi- } \\
\text { miento estudiantil cerca de mil altopar- } \\
\text { lantes portátiles último modelo para } \\
\text { usarlos en mítines y manifestaciones. } \\
\text { Entregaron aparatos entre los estu- } \\
\text { diantes de las universidades de } \\
\text { provincia: Puebla, Morelos, Sinaloa, } \\
\text { Chiapas, Chilpancingo, Monterrey, } \\
\text { Durango y Guadalajara). } \\
\text { Entregaron aparatos entre los estudiantes } \\
\text { del Valle de México: unAm, IPN, Normal } \\
\text { Superior, Chapingo, Iberoamericana, } \\
\text { Del Valle de México y otras escuelas. } \\
\text { En el restaurante de Sears Insurgentes } \\
\text { abastecía de alimentos a los conjurados } \\
\text { y ahí nació el cNH que no fue electo por } \\
\text { la base estudiantil, sino por el embajador } \\
\text { Freeman y la cis. }\end{array}$ \\
\hline
\end{tabular}




\begin{tabular}{|c|c|c|}
\hline $\begin{array}{l}\text { Estados } \\
\text { Unidos de } \\
\text { América }\end{array}$ & $\begin{array}{l}\text { Terry Cory } \\
\text { (agente de la CIA) }\end{array}$ & $\begin{array}{l}\text { Financió al movimiento estudiantil la } \\
\text { tarde del } 2 \text { de octubre, y dio la orden } \\
\text { para iniciar los disparos en la plaza de } \\
\text { las tres culturas. } \\
\text { Proporcionó armas y municiones a las } \\
\text { brigadas armadas, apostadas en los } \\
\text { edificios contiguos a la Plaza de las Tres } \\
\text { Culturas. }\end{array}$ \\
\hline $\begin{array}{l}\text { Estados } \\
\text { Unidos de } \\
\text { América }\end{array}$ & $\begin{array}{l}\text { Larry Terfiel } \\
\text { (agente de la cIA) }\end{array}$ & $\begin{array}{l}\text { Hizo contacto con los líderes estudian- } \\
\text { tiles de Sinaloa que le proveían de drogas, } \\
\text { en una avioneta las entregaba a los estu- } \\
\text { diantes, entre ellos a Sócrates A. Campos } \\
\text { Lemus cargamentos con valor de ochenta } \\
\text { mil dólares. }\end{array}$ \\
\hline Cuba & $\begin{array}{l}\text { Embajada } \\
\text { cubana en } \\
\text { México }\end{array}$ & $\begin{array}{l}\text { Estudiantes viajaron para tomar lecciones } \\
\text { de guerrilla, de subversión, de sabotaje. } \\
\text { Los estudiantes mexicanos que viajaron } \\
\text { a Cuba recibieron dinero y armas. } \\
\text { Lázaro Cárdenas recordó a Castro Ruz } \\
\text { el favor de cuando estuvo en México e } \\
\text { intervino para que fuera liberado y pidió } \\
\text { apoyo para la subversión en ciernes. }\end{array}$ \\
\hline $\begin{array}{l}\text { Unión } \\
\text { Soviética } \\
\text { (Rusia) }\end{array}$ & $\begin{array}{l}\text { Embajada rusa } \\
\text { en México }\end{array}$ & $\begin{array}{l}\text { Había células soviéticas entre profe- } \\
\text { sores y alumnos de casi todos los plan- } \\
\text { teles educativos de la UNAM y el IPN. } \\
\text { Aplican la estrategia de la Maquina } \\
\text { Infernal utilizada en Francia y en otros } \\
\text { países del mundo. }\end{array}$ \\
\hline Francia & $\begin{array}{l}\text { Activistas durante } \\
\text { el mayo francés }\end{array}$ & $\begin{array}{l}\text { Vinieron a México y durante semanas } \\
\text { cambiaron impresiones con líderes de la } \\
\text { UNAM, del IPN y de las Escueles Normales } \\
\text { y de Agricultura. }\end{array}$ \\
\hline Otros & $\begin{array}{l}\text { Pierre Salignay, } \\
\text { Jean Duval de } \\
\text { Nanterre }\end{array}$ & $\begin{array}{l}\text { Provocadores profesionales actuando en } \\
\text { México. }\end{array}$ \\
\hline Otros & $\begin{array}{l}\text { Prensa } \\
\text { internacional } \\
\text { Oriana Fallaci, } \\
\text { Heinrich Jaeceekc, } \\
\text { Claude Kiejman, } \\
\text { John Rodda, } \\
\text { Jean Claude } \\
\text { Le Vegue y } \\
\text { Dominique Izoard }\end{array}$ & $\begin{array}{l}\text { Dieron veracidad a infamias contra } \\
\text { México. } \\
\text { Publicaciones alarmistas y amarillistas } \\
\text { que aseguraban que México estaba "al } \\
\text { borde de la revolución comunista". } \\
\text { Hubo un ataque económico contra } \\
\text { México, se frenaron inversiones. }\end{array}$ \\
\hline
\end{tabular}

Legajos. Boletín del Archivo General de la Nación

46 Número 17 (septiembre-diciembre 2018) • ISSN: 0185-1926 • ISSN-e: 2448-8798 


\begin{tabular}{|c|c|c|}
\hline \multicolumn{3}{|c|}{ Ámbito Nacional } \\
\hline Nombre & $\begin{array}{l}\text { Dependencia o } \\
\text { persona }\end{array}$ & $\begin{array}{l}\text { Función } \\
\end{array}$ \\
\hline $\begin{array}{l}\text { Lázaro } \\
\text { Cárdenas del } \\
\text { Río }\end{array}$ & Expresidente & $\begin{array}{l}\text { Aliado incondicional del comunismo } \\
\text { internacional desde que fue presidente. } \\
\text { No pierde oportunidad de trabajar por } \\
\text { su instauración. }\end{array}$ \\
\hline $\begin{array}{l}\text { Heberto } \\
\text { Castillo } \\
\text { Martínez }\end{array}$ & $\begin{array}{l}\text { Profesor de la } \\
\text { UNAM y del IPN }\end{array}$ & $\begin{array}{l}\text { Contacto con el comunismo interna- } \\
\text { cional. } \\
\text { Dirige el movimiento estudiantil. } \\
\text { Obtiene apoyo de diverso tipo con el } \\
\text { general Lázaro Cárdenas. }\end{array}$ \\
\hline $\begin{array}{l}\text { Javier Barros } \\
\text { Sierra }\end{array}$ & $\begin{array}{l}\text { Rector de la } \\
\text { UNAM }\end{array}$ & $\begin{array}{l}\text { Permitió que en la UNAM se insertaran } \\
\text { personas ajenas a la institución. } \\
\text { La Ciudad Universitaria se convirtió en } \\
\text { un cuartel de guerrilleros. } \\
\text { Creía encarnar la figura moral para } \\
\text { jóvenes y animaba a los líderes del CNH. }\end{array}$ \\
\hline $\begin{array}{l}\text { Maestros } \\
\text { universitarios } \\
\text { y politécnicos }\end{array}$ & $\begin{array}{l}\text { Ifigenia Martínez, } \\
\text { Víctor Flores } \\
\text { Olea, Elí de } \\
\text { Gortari, Fausto } \\
\text { Trejo, Víctor } \\
\text { Rico Galán, José } \\
\text { Revueltas } \\
\end{array}$ & $\begin{array}{l}\text { Influían maliciosamente en sus alumnos. } \\
\text { Formaron la Coalición de Profesores } \\
\text { de Enseñanza Media y Superior Pro } \\
\text { Libertades Democráticas. }\end{array}$ \\
\hline $\begin{array}{l}\text { Políticos } \\
\text { resentidos } \\
\text { del anterior } \\
\text { gobierno }\end{array}$ & $\begin{array}{l}\text { Carlos Alberto } \\
\text { Madrazo, } \\
\text { Ernesto P. } \\
\text { Uruchurtu, } \\
\text { Humberto } \\
\text { Romero, Benito } \\
\text { Coquet, Gilberto } \\
\text { Flores Muñoz, } \\
\text { Donato Miranda } \\
\text { Fonseca, José } \\
\text { Gómez Huerta, } \\
\text { Roberto Barrios, } \\
\text { José Álvarez } \\
\text { Amézquita, } \\
\text { Braulio } \\
\text { Maldonado, } \\
\text { Ángel Veraza, } \\
\text { Víctor M. } \\
\text { Urquidi, Elena } \\
\text { Garro }\end{array}$ & $\begin{array}{l}\text { Financiaron una base estudiantil dispo- } \\
\text { nible para hacer desmanes desde 1964, } \\
\text { como opción para derrocar al gobierno } \\
\text { de Díaz Ordaz. } \\
\text { Pagaban a los estudiantes un sueldo de } \\
500 \text { pesos mensuales. } \\
\text { Dispusieron de un fondo de } 50 \text { millones } \\
\text { de pesos para tal efecto. } \\
\text { Destinaban recursos económicos al } \\
\text { movimiento estudiantil que salían de } \\
\text { los presupuestos del Issste, del IMss y } \\
\text { de la Oficina de Relaciones Públicas de } \\
\text { Palacio Nacional y la Lotería Nacional. }\end{array}$ \\
\hline
\end{tabular}




\begin{tabular}{|c|c|c|}
\hline $\begin{array}{l}\text { Políticos } \\
\text { oportunistas } \\
\text { del actual } \\
\text { gobierno }\end{array}$ & $\begin{array}{l}\text { Dr. Emilio } \\
\text { Martínez } \\
\text { Manautou } \\
\text { secretario de la } \\
\text { Presidencia de la } \\
\text { República } \\
\text { Luis Echeverría } \\
\text { Álvarez } \\
\text { Secretario de } \\
\text { Gobernación }\end{array}$ & $\begin{array}{l}\text { Martínez Manautou le echaba leña al } \\
\text { fuego para quemar al regente (Corona } \\
\text { del Rosal) y al secretario Echeverría. } \\
\text { Mantiene relación con personajes de filia- } \\
\text { ción comunista que cobran en la nómina } \\
\text { de la Presidencia. } \\
\text { Echeverría tiene acercamiento con maes- } \\
\text { tros universitarios comunistas a quienes } \\
\text { incorporó como asesores a líderes del } \\
\text { movimiento de } 1968 \text {. }\end{array}$ \\
\hline $\begin{array}{l}\text { Intelectuales } \\
\text { y artistas }\end{array}$ & $\begin{array}{l}\text { Elena Garro, Dr. } \\
\text { Víctor Urquidi, } \\
\text { Jesús Silva } \\
\text { Herzog, José } \\
\text { Luis Cuevas, } \\
\text { Leopoldo Zea } \\
\text { y Rosario } \\
\text { Castellanos }\end{array}$ & $\begin{array}{l}\text { De acuerdo con las declaraciones de Áyax } \\
\text { Segura, Gilberto Guevara, Marcelino } \\
\text { Perelló y Sócrates Campos, contribuían } \\
\text { con recursos económicos para el movi- } \\
\text { miento estudiantil. }\end{array}$ \\
\hline Prensa & $\begin{array}{l}\text { Julio Scherer } \\
\text { García del diario } \\
\text { Excélsior } \\
\text { Mario Menéndez } \\
\text { Rodríguez } \\
\text { director de la } \\
\text { revista ¿Por Qué? }\end{array}$ & $\begin{array}{l}\text { En las oficinas de Excélsior nació, se } \\
\text { dirigió y controló mucho de lo ocurrido } \\
\text { en el } 68 \text {. } \\
\text { La embajada rusa con apoyo del PGM } \\
\text { planeó la llegada de Scherer a Excél- } \\
\text { sior para usarlo como medio de lucha y } \\
\text { propaganda comunista. } \\
\text { El embajador Freeman trató con Scherer } \\
\text { para que Excélsior desarrollara una } \\
\text { campaña en contra de Díaz Ordaz muy } \\
\text { bien pagada. } \\
\text { Diariamente hacía propaganda comu- } \\
\text { nista, azuzaban a estudiantes, campe- } \\
\text { sinos, obreros a que alteraran el orden. } \\
\text { Menéndez Rodríguez recibe dinero de } \\
\text { agentes de la cia para formar grupos } \\
\text { guerrilleros, su revista es parte de la } \\
\text { campaña de desprestigio pagada en } \\
\text { dólares. }\end{array}$ \\
\hline
\end{tabular}

Fuente: Luis Gutiérrez Oropeza, La realidad de los acontecimientos de 1968, México, [L. Gutiérrez Oropeza], 1996. 


\section{Lealtad perpetua}

Como una sombra, los poblanos se seguían el uno al otro, en los momentos de gloria y de desasosiego. Era común ver a Gutiérrez Oropeza en las fotografías de la época, flanqueando al mandatario. La lealtad que profesó Gutiérrez a Díaz Ordaz fue a prueba de todo. Cubrió la espalda del presidente cuando éste había fallecido ${ }^{78}$ y mantuvo esa defensa durante toda su vida, no lo traicionó, aun sintiendo acercarse el inevitable fin de su vida. ${ }^{79}$ Desde 1998 el general Gutiérrez Oropeza fue acusado directamente por los exdirigentes del Consejo Nacional de Huelga como culpable de la represión contra el movimiento estudiantil y cómplice del delito de genocidio. ${ }^{80}$ En una entrevista concedida a La Fornada el 26 de septiembre de 1998 negó toda responsabilidad suya y del entonces presidente Gustavo Díaz Ordaz. Dijo: "Los únicos culpables de los hechos sucedidos a diez días de la inauguración de las Olimpiadas México 68, fueron los que pagaron y se beneficiaron del movimiento, entre los que destacan Rusia, vía Cuba, así como Estados Unidos". ${ }^{81}$

Luego de que se hicieran públicos los documentos del general Marcelino García Barragán en 1999 y que fueron divulgados en

\footnotetext{
${ }^{78}$ En el XVIII aniversario luctuoso de Díaz Ordaz en 1997, Gutiérrez Oropeza fue el único orador. Recordó a su "amigo y jefe", "ante familiares, amigos y colaboradores de Díaz Ordaz, el general Gutiérrez Oropeza dijo que, pese a ataques, injurias y amenazas, el expresidente, 'mantuvo firme el timón de la patria, para conservarla en calma y en paz. En esos momentos difíciles, México tuvo presidente; no era su prestigio el que estuvo en peligro, sino el de la patria"”. José Antonio Román, "Desorientación e ignorancia sobre los hechos del 68: Gutiérrez Oropeza", La fornada, 16 de julio de 1997, p. 20.

${ }^{79}$ Jesús Arana, "Gutiérrez Oropeza murió siendo leal al expresidente Díaz Ordaz, afirma su hijo", en La jornada, 22 de marzo de 2007, p. 32.

${ }^{80}$ Sin autor, "Tlatelolco 68: Gutiérrez Oropeza es llamado a comparecer", Proceso, 29 de octubre de 2002, p. 18.

${ }^{81}$ Sin autor, "Tlatelolco 68: Gutiérrez Oropeza es llamado a comparecer", Proceso, 29 de octubre de 2002, p. 18.
} 
Una imagen deformada por la distancia, por el tiempo y por la historia".

Para el ministro del Interior, "en ese teryeno", el gobierno mexicano puede "hacer arie ichivingiv

A la pregunta de si estaba a gusto con la cooperación judicial entre su gobierno y el de México, Oreja respondió: "pơdemos mejorar y trabajar en esa línea de exigencia

\section{"Es necesaria una explicación oficial", afirmó}

Blanche Petrich y Triunfo Elizalde $\square$ El general Luis Gutiérrez Oropeza, ex jefe de Estado Mayor Presidencial del ex presidente Gustavo Díaz Ordaz, aportó dos nuevos elementos a la versión oficial sobre la matanza de Tlatelolco " $\mathrm{y}$ ahora está obligado a ofrecer pruebas documentales de lo que dijo", señaló Raúl Alvarez Garín, quien en la época del movimiento estudiantil sesentaiochero fue miembro del Comité Nacional de Huelga.

Al retomar la exigencia de la Comisión de la Verdad, creada en 1993 con motivo del 25 aniversario de la Noche de Tlate- recomendo en su momento la ya disuelta Comisión de la Verdad. "Todas las acciones militares parten de una orden superior específica. Salvo el primer eslabón, en el cual es probable que Dfaz Ordaz haya dado verbalmente la orden al secretario de Defensa de reprimir, el resto de la cadena debe estar claramente indicado en memoranda, oficios y demás". Indica que pueden encontrarse datos para reconstruir la historía de la masacre en la Sedena, en la propia Presidencia, en la Secretaría de Gobernación, el Departamento del Distrito Federal y la Secretaría de Seguridad Pública- y los gest

Las "lín mejoras: sino solic vos y jud "paises a titud fren rorismo'

En el c ción de que sign que iban dura de 1 En este sino de : rras (Pol Doming les contr armada una mej

Los pre:

El minis

Herri B ETA, $y$ d

Imagen 12. "Gutiérrez Oropeza debe probar sus palabras, dice Álvarez Garín", La Fornada, 17 de julio de 1997, p. 13.

el libro Parte de guerra, en el cual es señalado como responsable de apostar diez francotiradores en la Plaza de las Tres Culturas, los señalamientos crecieron, se hicieron más directos y enérgicos. Pero esa presión no lo dobló, se mantuvo firme; en junio de 1999 "Gutiérrez Oropeza negó todo: 'Yo no tenía nada que ver con los líos del 2 de octubre', dijo el militar retirado, y desmintió haber enviado francotiradores militares a Tlatelolco". 82

Aliado de un gobierno enérgico, dice que "sufrieron muchos - sobre todo aquellos que se colocaron fuera de la ley-, pero si un gobierno es débil, la población necesariamente sufrirá las

${ }^{82}$ Juan Jesús Aznárez, "Una investigación culpa a un reducido grupo de militares de la matanza de Tlatelolco", 29 de junio de 1999, El País Digital, http://www1.udel. edu/leipzig/060299/elb290699.htm [consultado el 6 de febrero de 2018]. 
consecuencias. El Lic. Gustavo Díaz Ordaz preservó y entregó el país intacto". 83

\section{A modo de conclusión}

Murió el 19 de marzo de 2007, sin haber sido castigado penalmente por los acontecimientos del 2 de octubre y de su colaboración en la formación de grupos paramilitares que, en las décadas de 1970 y 1980, dieron vida a la guerra sucia. Se llevó a la tumba la información sobre los responsables directos de la provocación en Tlatelolco. A pesar de haber escrito al respecto, nunca se despegó de la versión oficial primigenia, esto debido a la responsabilidad que cargaba y a la información a que tuvo acceso. Para Gutiérrez Oropeza, "Díaz Ordaz se vio obligado y suprimió la agresión y el intento subversivo de desestabilizar al país". ${ }^{44}$

A diferencia de otros actores de primera línea, como el ex secretario de la Defensa Marcelino García Barragán, Gutiérrez Oropeza no se movió un milímetro de la versión oficial; hasta el final de sus días la sostuvo. La realidad de los acontecimientos ha quedado cifrada en su texto; sin embargo, la verdad de la decisión de terminar con el movimiento estudiantil la guardó para sí, congruente con el pacto de lealtad. Paulatinamente se han ido develando las escenas tras bambalinas en las alcobas del poder aquel otoño de 1968. A medida que aparecen nuevos testimonios, documentos y estudios, el horizonte se expande y logramos conocer situaciones negadas. La historia ya está haciendo el trabajo de juez, ha señalado responsables y culpables, pero no está en ella hacer justicia; únicamente colabora, lo cual es otro asunto.

${ }^{83}$ Gutiérrez Oropeza, La realidad de los acontecimientos, p. 69.

${ }^{84}$ Gutiérrez Oropeza, La realidad de los acontecimientos, p. 75. 


\section{Fuentes}

\section{Acervos}

AGN Archivo General de la Nación

Ahmebc Archivo y Museo de la Escuela Bancaria y Comercial

Biblioteca Daniel Cosío Villegas de El Colegio de México

Hemeroteca Miguel Lerdo de Tejada

Hemeroteca Nacional de México

\section{Hemerografía}

Proceso, Ciudad de México

Política, Ciudad de México

El Día, Ciudad de México

La Prensa, Ciudad de México

La Fornada, Ciudad de México

El País Digital, Ciudad de México

Excélsior, Ciudad de México

El Universal, Ciudad de México

¿Por qué?, Ciudad de México

\section{Documentales}

López, Leopoldo, El grito México 1968, 1969.

Mendoza, Carlos, Tlatelolco: las claves de la masacre, 2002.

\section{Bibliografía}

Aguayo Quezada, Sergio, De Tlatelolco a Ayotzinapa: las violencias del Estado, México, Ediciones Proceso, 2015.

Álvarez Garín, Raúl, La estela de Tlatelolco. Una reconstrucción histórica del movimiento estudiantil de 68, México, Grijalbo, 1998. 
Camp, Roderic Ai, Mexican Political Biographies, 1935-1993, 3a. Ed., Austin, University of Texas Press, 1995.

Cárdenas, Cuauhtémoc, Sobre mis pasos, México, Aguilar, 2010.

Carrillo Olea, Jorge, México en riesgo: una visión personal sobre un Estado a la defensiva, México, Grijalbo, 2011.

Corona del Rosal, Alfonso, Mis memorias políticas, México, Grijalbo, 1995.

González de Alba, Luis, Otros días, otros años, México, Planeta, 2013.

Gutiérrez Oropeza, Luis, Gustavo Díaz Ordaz, el hombre, el gobernante, México, Gustavo de Anda ed., 1988.

La realidad de los acontecimientos de 1968, México, [L. Gutiérrez Oropeza], 1996.

Krauze, Enrique, La presidencia Imperial, México, Tusquets Editores, 1997.

Morley, Jefferson, Nuestro hombre en México. Winston Scott y la historia oculta de la CIA, México, Taurus, 2010.

Scherer García, Julio, y Carlos Monsiváis, Parte de guerra. Tlatelolco 1968. Documentos del general Marcelino García Barragán. Los hechos y la historia, México, Aguilar, 1999.

Semo, Enrique (coord.), México un pueblo en la historia, t. 4, México, Editorial Nueva Imagen-UAP, 1982.

Tasso, Pablo, "La historiografía oficial de 1968", tesis de doctorado en Historia, inédita, Universidad Autónoma Metropolitana-Azcapotzalco, 2014. 
Urrutia Castro, Manuel, Trampa en Tlatelolco, sintesis de una felonia hacia México, México, M. Urrutia Castro, 1981.

Veledíaz, Juan, Finetes de Tlatelolco. Marcelino García Barragán y otros retratos del ejército mexicano, México, Ediciones Proceso, 2017.

Villalpando, José Manuel, "Política y ejército, 1945-1994", en Javier Garciadiego (coord.), El ejército mexicano 100 años de historia, México, El Colegio de México, 2014. 